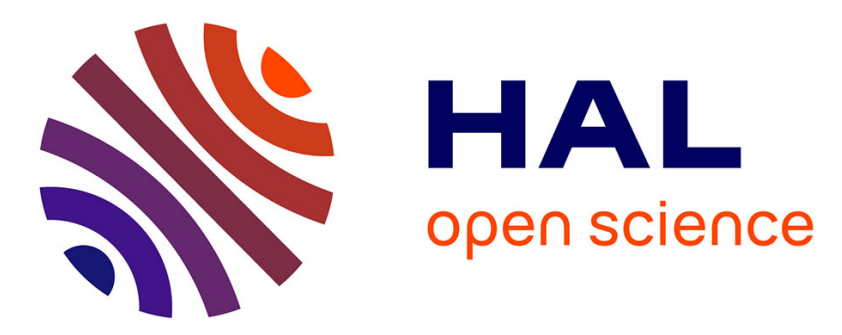

\title{
Vibration Characteristics and Persistence of Poloxamer- or Phospholipid-Coated Single Microbubbles under Ultrasound Irradiation
}

Marie Pierre Krafft, Hiraku Tabata, Daisuke Koyama, Mami Matsukawa, Kenji Yoshida

\section{To cite this version:}

Marie Pierre Krafft, Hiraku Tabata, Daisuke Koyama, Mami Matsukawa, Kenji Yoshida. Vibration Characteristics and Persistence of Poloxamer- or Phospholipid-Coated Single Microbubbles under Ultrasound Irradiation. Langmuir, 2019. hal-03018455

\section{HAL Id: hal-03018455 \\ https://hal.science/hal-03018455}

Submitted on 22 Nov 2020

HAL is a multi-disciplinary open access archive for the deposit and dissemination of scientific research documents, whether they are published or not. The documents may come from teaching and research institutions in France or abroad, or from public or private research centers.
L'archive ouverte pluridisciplinaire HAL, est destinée au dépôt et à la diffusion de documents scientifiques de niveau recherche, publiés ou non, émanant des établissements d'enseignement et de recherche français ou étrangers, des laboratoires publics ou privés. 
This document is confidential and is proprietary to the American Chemical Society and its authors. Do not copy or disclose without written permission. If you have received this item in error, notify the sender and delete all copies.

\section{Vibration characteristics and persistence of poloxamer- or phospholipid-coated single microbubbles under ultrasound irradiation}

\begin{tabular}{|r|l|}
\hline Journal: & Langmuir \\
\hline Manuscript ID & Draft \\
\hline Manuscript Type: & Article \\
\hline Aute Submitted by the & $\mathrm{n} / \mathrm{a}$ \\
\hline Complete List of Authors: & $\begin{array}{l}\text { Tabata, Hiraku; Doshisha Daigaku } \\
\text { Koyama, Daisuke; Doshisha Daigaku } \\
\text { Matsukawa, Mami; Doshisha Univ, Faculty of Science and Engineering } \\
\text { Yoshida, Kenji; Chiba University, Center for Frontier Medical Engineering } \\
\text { Krafft, Marie Pierre; Université de Strasbourg, Institut Charles Sadron } \\
\text { (CNRS), Systèmes Organisés Fluorés à Finalités Thérapeutiques (SOFFT) }\end{array}$ \\
\hline
\end{tabular}

\section{SCHOLARONE \\ Manuscripts}




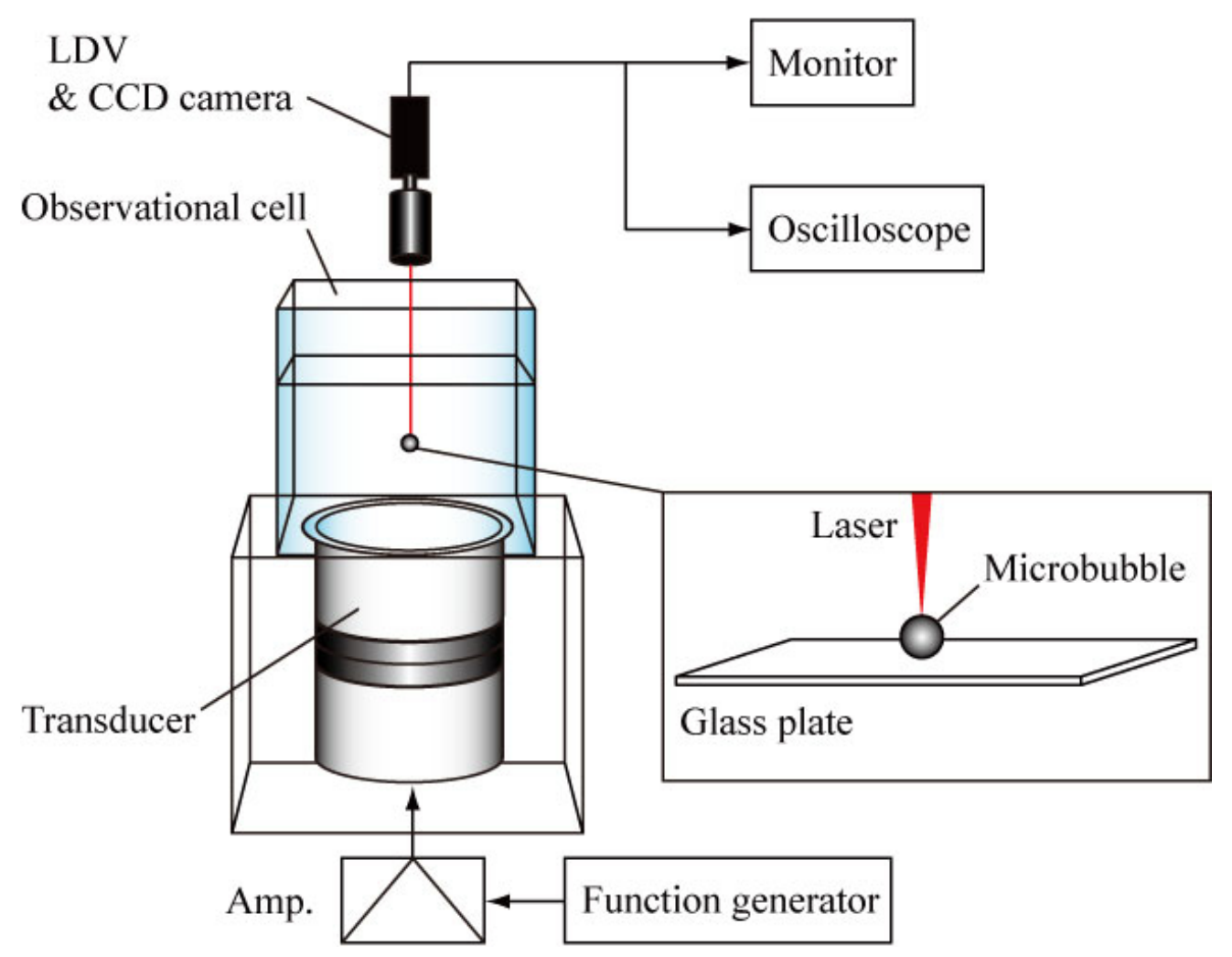

Figure 1. System for single-bubble vibration observation using an ultrasound transducer and laser Doppler vibrometer (LDV).

$225 \times 176 \mathrm{~mm}(72 \times 72 \mathrm{DPI})$ 

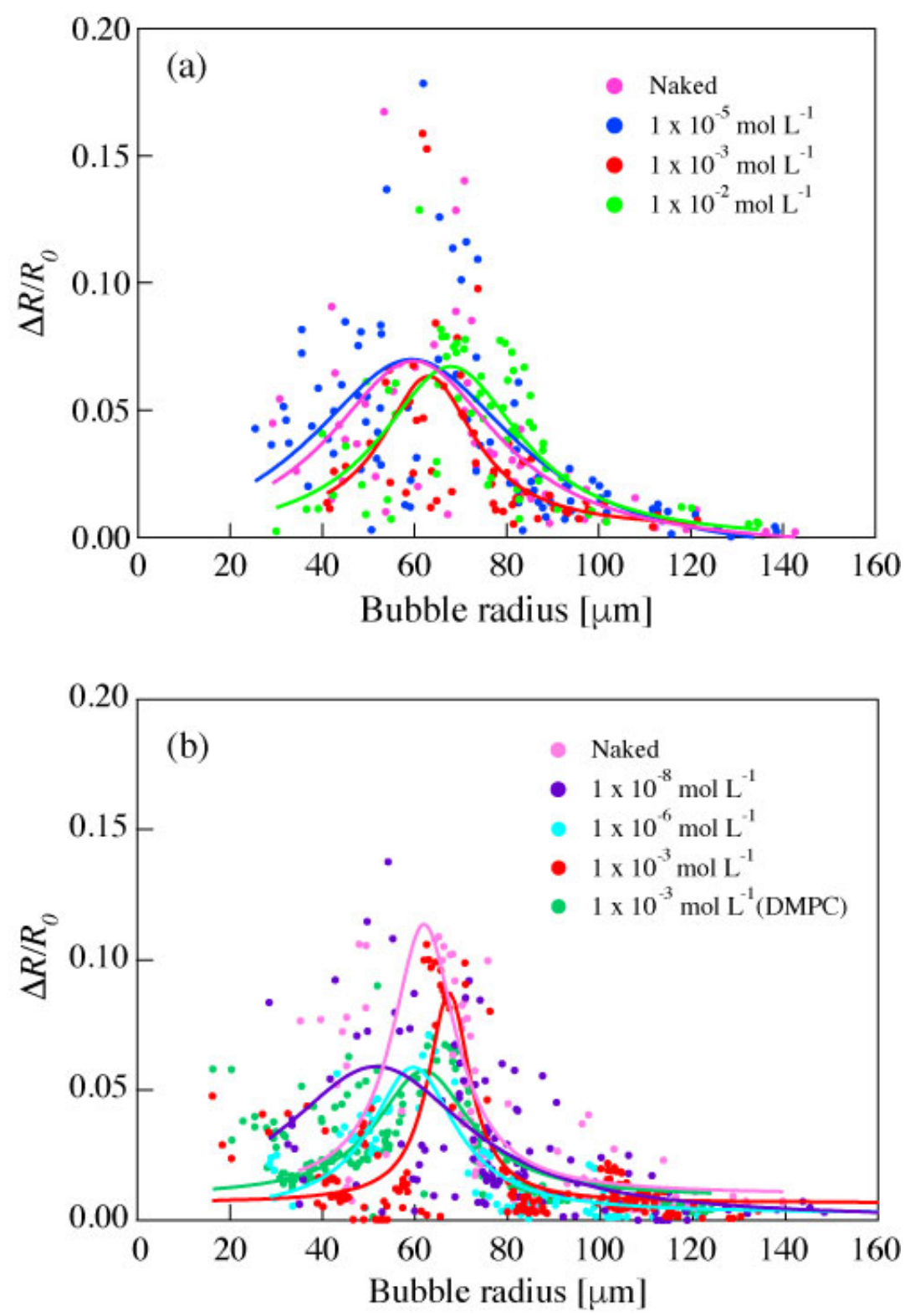

Relationships between the initial bubble radius and normalized displacement amplitude for (a) air-filled microbubbles $\left(\Delta R / R_{0}\right)$ coated with Pluronic F-68 at concentrations of 0 (naked), $1 \times 10^{-5}, 1 \times 10^{-3}$, and 1 $\times 10^{-2} \mathrm{~mol} \mathrm{~L}^{-1}$ and (b) PFH-filled microbubbles $\left(\left(\Delta R / R_{0}\right)\right)$ coated with Pluronic F-68 and DMPC at concentrations of 0 (naked), $1 \times 10^{-8}, 1 \times 10^{-6}, 1 \times 10^{-3} \mathrm{~mol} \mathrm{~L}^{-1}$ and $1 \times 10^{-3} \mathrm{~mol} \mathrm{~L}^{-1}$ (DMPC). Fitting curves were obtained using the Lorentz distribution.

$176 \times 258 \mathrm{~mm}(72 \times 72 \mathrm{DPI})$ 

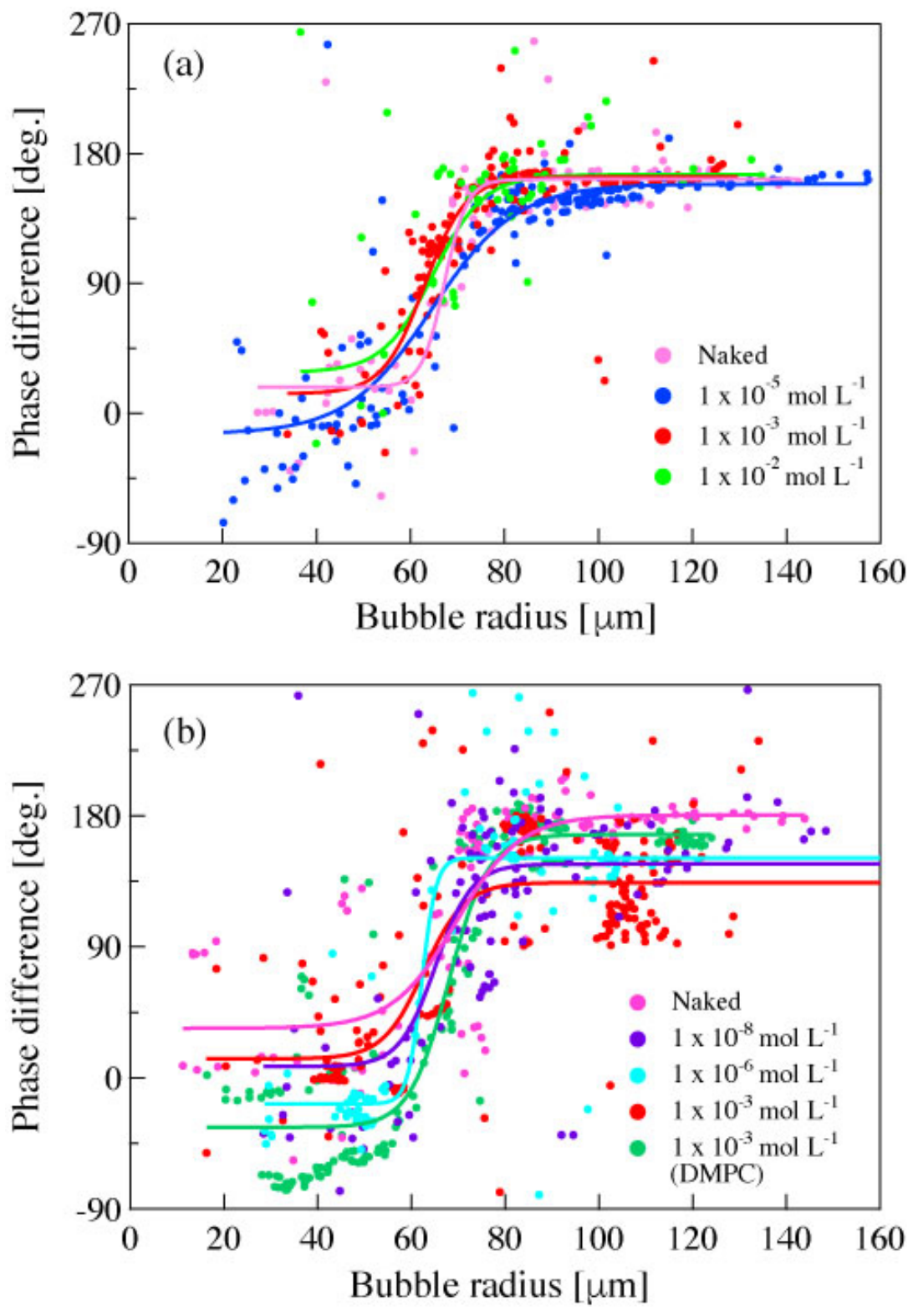

Relationships between bubble radius and phase difference between the sound pressure amplitude and vibration of (a) air-filled microbubbles coated with Pluronic F-68 with concentrations of 0 (naked), $1 \times 10^{-5}$, $1 \times 10^{-3}$, and $1 \times 10^{-2} \mathrm{~mol} \mathrm{~L}^{-1}$ and (b) PFH-filled microbubbles $\left(\Delta R / R_{0}\right)$ coated with Pluronic F-68 and DMPC at concentrations of 0 (naked), $1 \times 10^{-8}, 1 \times 10^{-6}, 1 \times 10^{-3} \mathrm{~mol} \mathrm{~L}^{-1}$ and $1 \times 10^{-3} \mathrm{~mol} \mathrm{~L}^{-1}(\mathrm{DMPC})$ Fitting curves were obtained using the sigmoid distribution.

$176 \times 255 \mathrm{~mm}(72 \times 72 \mathrm{DPI})$ 


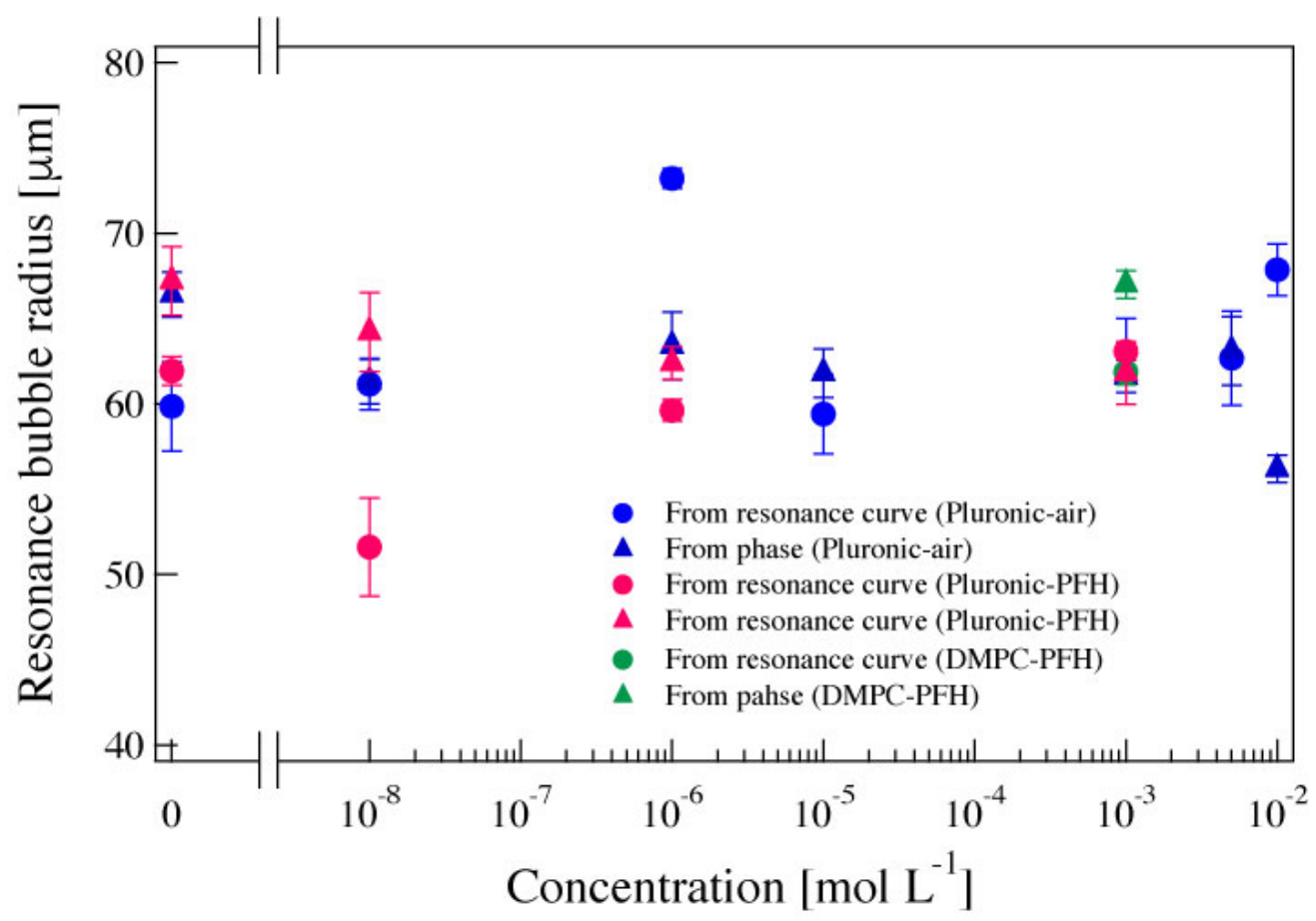

Relationship between Pluronic F-68 concentration and the resonance bubble radius estimated from the resonance curves (Fig. 2) and phase characteristics (Fig. 3). The blue circle and triangle describe air-bubble coated with Pluronic-F68. The pink circle and triangle describe PFH-bubble coated with Pluronic-F68. The green circle and triangle describe PFH-bubble coated with DMPC.

$252 \times 176 \mathrm{~mm}(72 \times 72$ DPI $)$ 


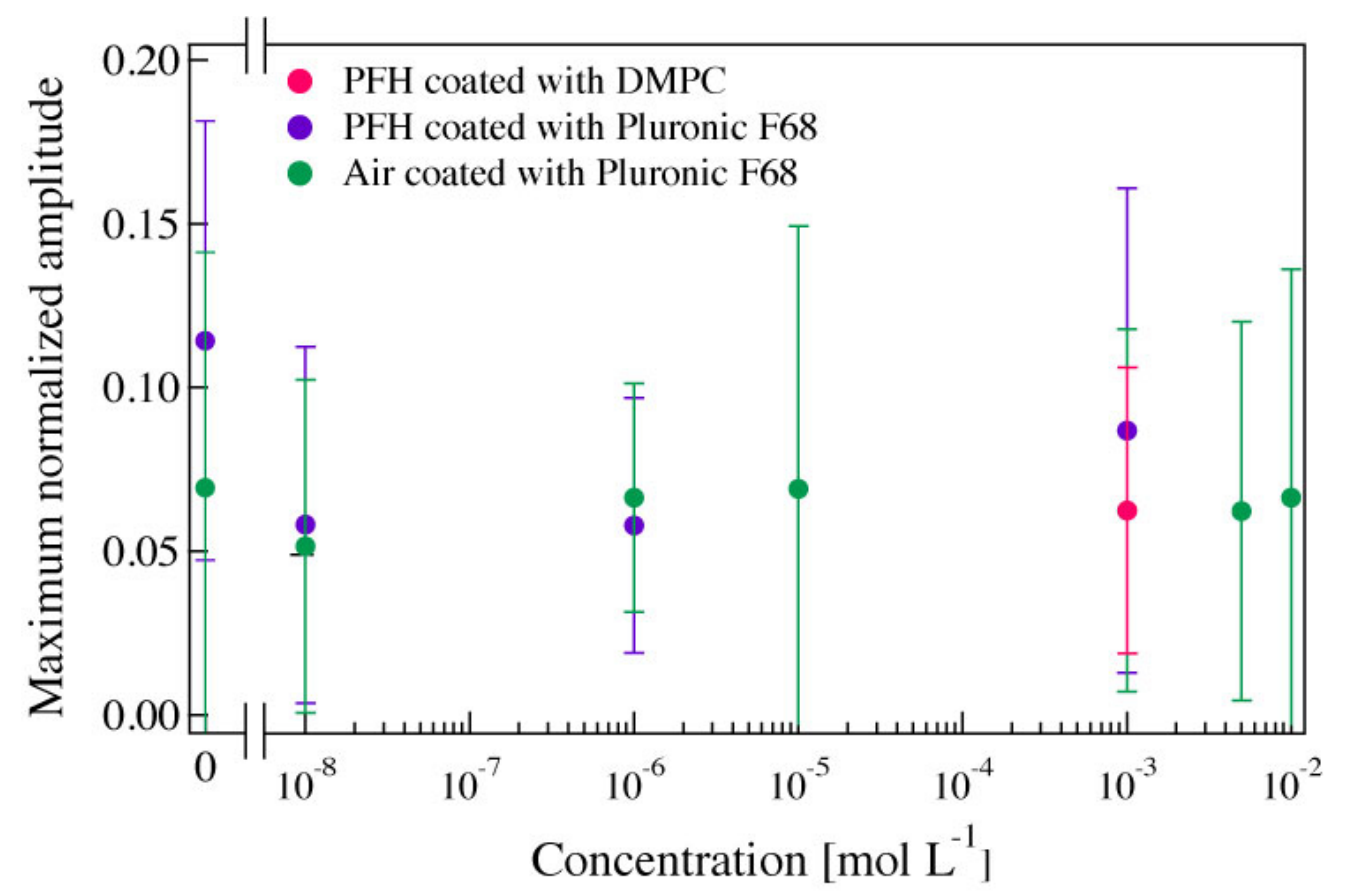

Relationship between Pluronic F-68 concentration and the maximum vibration amplitude of the microbubbles. The green circle describes air-bubble coated with Pluronic-F68. The purple one describes PFHbubble coated with Pluronic-F68. The pink one describes PFH-bubble coated with DMPC.

$260 \times 176 \mathrm{~mm}(72 \times 72$ DPI $)$ 


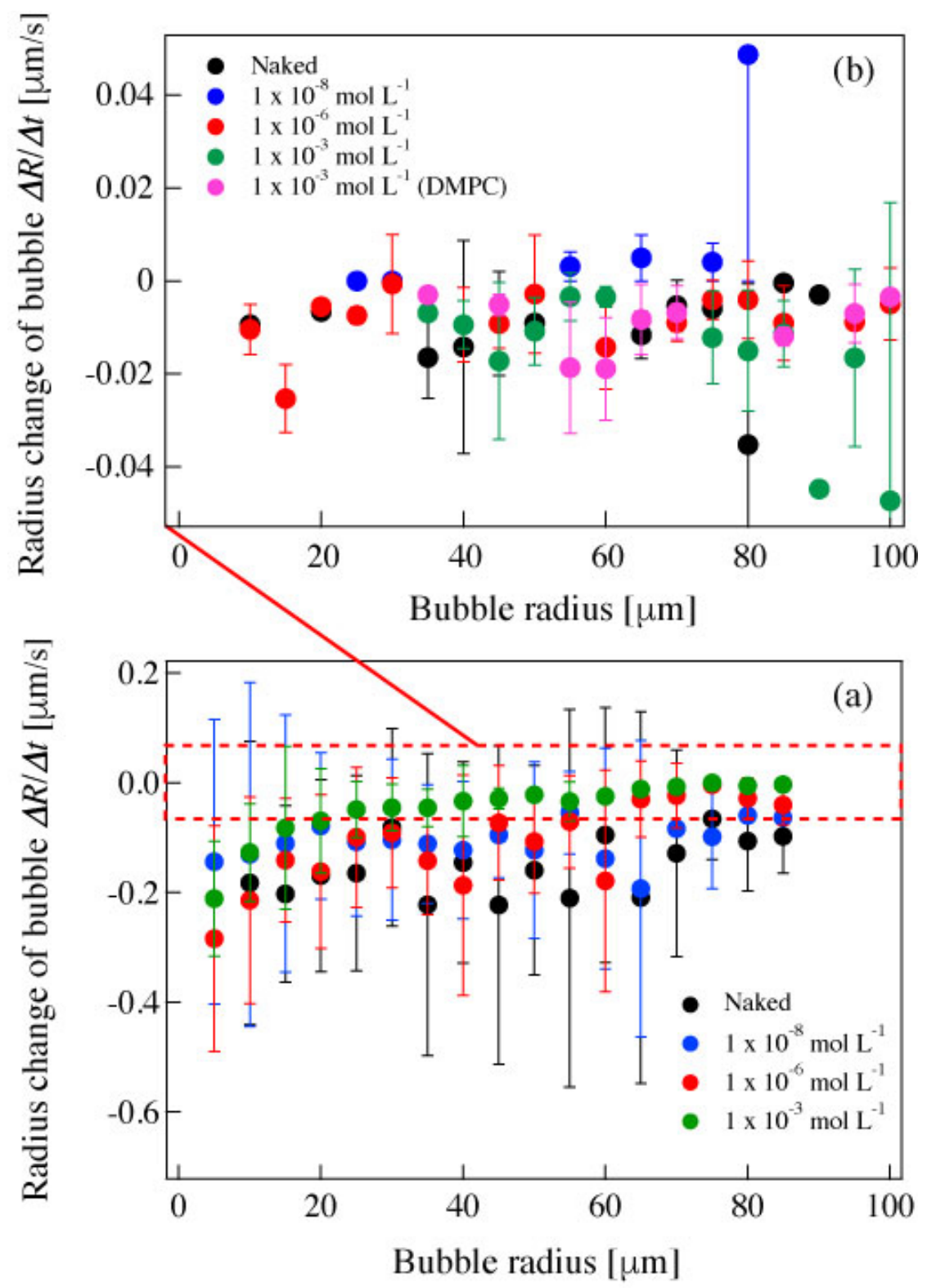

Temporal changes in the radius of (a) air-bubble coated with Pluronic-F68 and (b) PFH-bubble coated with Pluronic-F68 and DMPC.

$176 \times 247 \mathrm{~mm}(72 \times 72 \mathrm{DPI})$ 


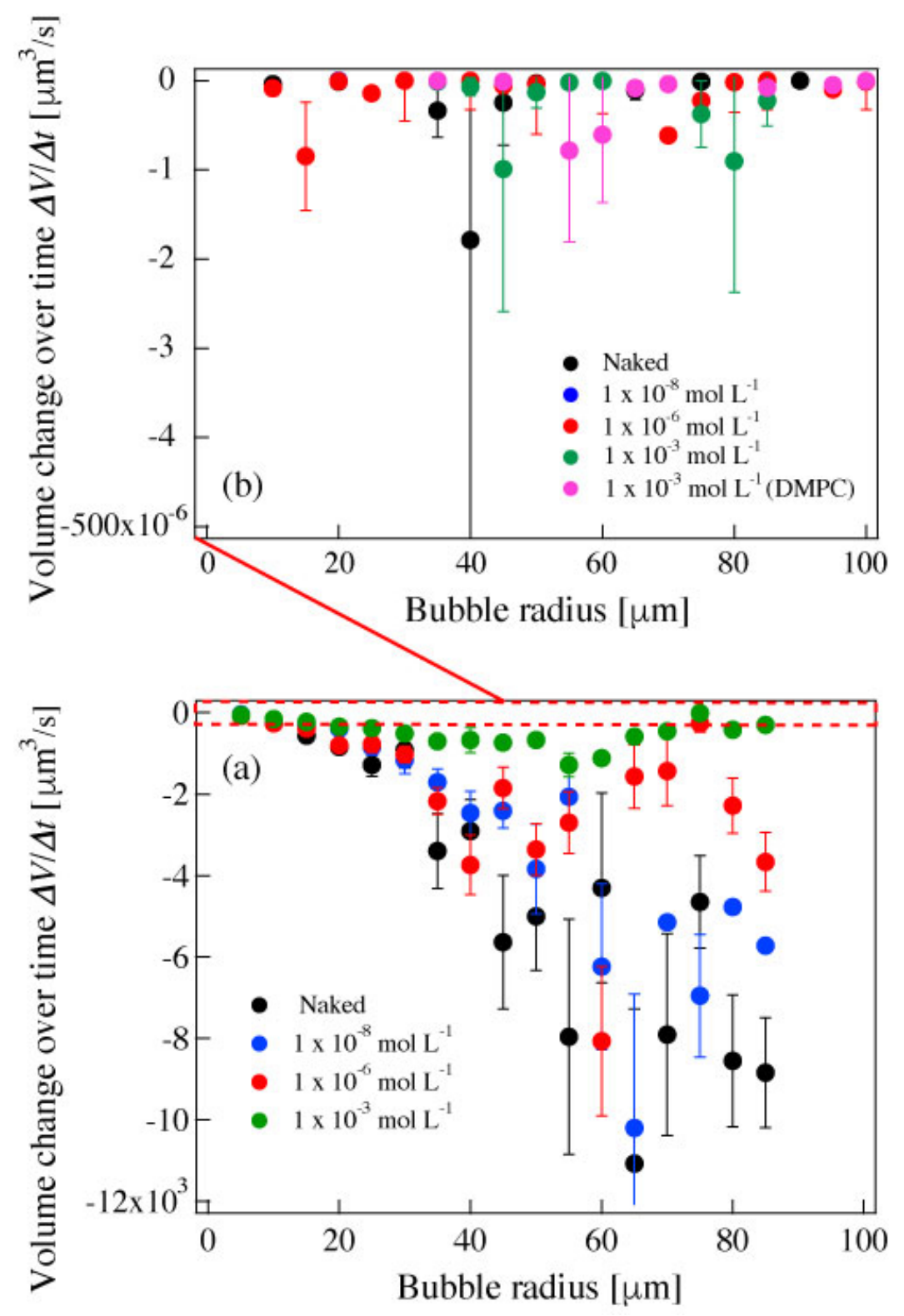

Temporal changes in the volume of (a) air-bubble coated with Pluronic-F68 and (b) PFH-bubble coated with Pluronic-F68 and DMPC.

$176 \times 262 \mathrm{~mm}(72 \times 72 \mathrm{DPI})$ 

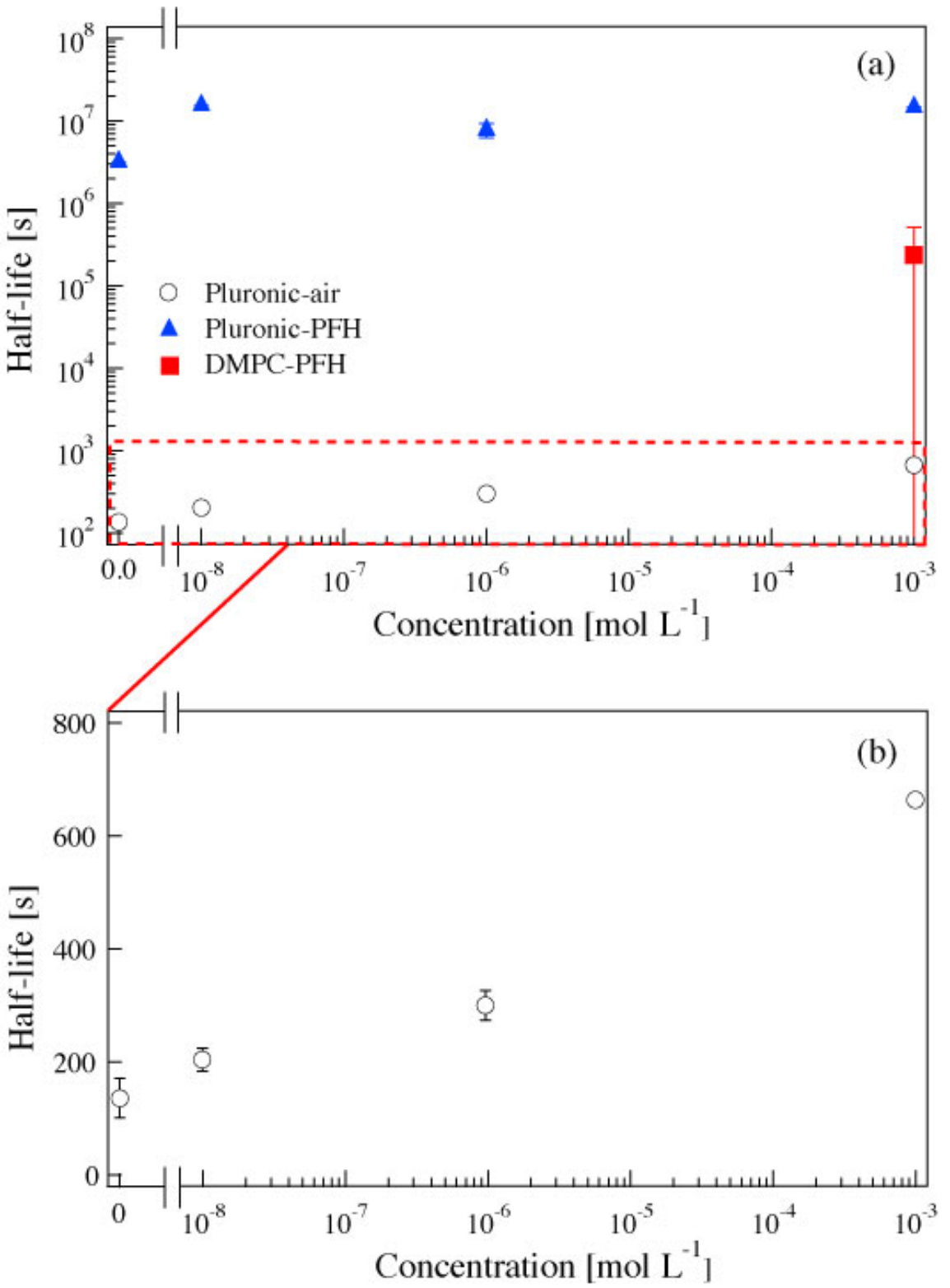

Relationship between concentration of Pluronic F-68 and DMPC and the half-life of microbubbles resonating under ultrasound exposure at $38.8 \mathrm{kHz}$. The hollow circle shows air-bubble coated with Pluronic-F68 and the triangle shows PFH-bubble coated with Pluronic-F68. The square shows PFH-bubble coated with DMPC.

$186 \times 256 \mathrm{~mm}(72 \times 72 \mathrm{DPI})$ 


\title{
Vibration Characteristics and Persistence of Poloxamer- or Phospholipid-Coated Single Microbubbles under Ultrasound Irradiation
}

\author{
Hiraku Tabata ${ }^{1}$, Daisuke Koyama ${ }^{1,}$, , Mami Matsukawa ${ }^{1}$, Kenji Yoshida ${ }^{2}$, Marie Pierre Krafft ${ }^{3}$ \\ ${ }^{1}$ Faculty of Science and Engineering, Doshisha University, 1-3 Tataramiyakodani, Kyotanabe, Kyoto \\ 610-0321, Japan \\ ${ }^{2}$ Center for Frontier Medical Engineering, Chiba University, 1-33 Yayoicho, Inage-ku, Chiba \\ 263-8522, Japan \\ ${ }^{3}$ Institut Charles Sadron (CNRS), University of Strasbourg, 23 rue du Loess, 67034 Strasbourg, \\ France \\ *dkoyama@mail.doshisha.ac.jp
}

\begin{abstract}
Microbubbles shelled with soft materials are expected to find applications as ultrasound-sensitive drug delivery systems, including through sonoporation. Microbubbles with specific vibrational characteristics and long intravascular persistence are required for clinical uses. To achieve this aim, the kinetics of the microbubble shell components at the gas/liquid interface while being subjected to ultrasound need to be better understood. This paper investigates the vibration characteristics and lifetime of single microbubbles coated with a poloxamer surfactant, Pluronic F-68, and 1,2-dimyristoyl-sn-glycero-3-phosphocholine (DMPC) under ultrasound irradiation. Air- and perfluorohexane (PFH)-filled microbubbles coated with Pluronic F-68 and DMPC at several concentrations ( 0 to $\left.10^{-2} \mathrm{~mol} \mathrm{~L}^{-1}\right)$ were produced. An optical measurement system using a laser Doppler vibrometer and microscope was used to observe the radial vibration mode of single microbubbles. The vibrational displacement amplitude and resonance radius of Pluronic- or DMPC-coated microbubbles were found to depend very little on the concentrations. The resonance radius was around $65 \mu \mathrm{m}$ at $38.8 \mathrm{kHz}$ under all the experimental conditions investigated. The lifetime of the microbubbles was investigated simultaneously by measuring their temporal change in volume, and it was increased with Pluronic concentration. Remarkably, the oscillation of the bubble has an effect on the bubble lifetime. In other words, the diffusion of the inner gas accelerates at resonance radius.
\end{abstract}

\section{Introduction}

Microbubbles are attractive for medical applications such as ultrasound contrast imaging and ultrasound-assisted drug delivery [1-4]. In these applications, the microbubbles are coated with either soft materials such as self-assembled molecular surfactants (e.g. phospholipids) or harder 
polymeric materials (e.g. poly(d,l-lactide-co-glycolide) to hinder the diffusion of the internal gases when the bubbles are injected in the vasculature and circulate through the body via blood vessels [5-7]. However, much more stable, polymeric shells considerably dampen the capacity for bubbles to resonate. To serve as drug and gene carriers, bubbles need to persist in the circulation system for hours to days [8-15]. The contraction and expansion of microbubbles under the effect of ultrasound irradiation, that is, bubble vibration, is a critical feature for ultrasound contrast imaging to enhance echo contrast. When used for delivery, collapse of the microbubbles can be initiated by ultrasound irradiation, which induces microjets and provokes the release of the drug or gene to cells. The effects of bubble collapse on tissues and their safety have been investigated [16-19]. Yoshikawa's group reported the effects of ultrasound on deoxyribonucleic acid (DNA) and measured the breaking of doubled-strand DNA under sonication at low ultrasound frequency [20,21]. Cavitation of microbubbles induced by high-intensity ultrasound increases local temperature and can enhance therapeutic effects [22-25].

There have been many reports on the vibration and collapse of microbubbles under ultrasound irradiation [26-31]. The effect of the shell of the microbubbles on their response to ultrasound vibration can be characterized by comparison with a free air bubble with no surrounding shell. Church [32], Sharker et al. [33], and Marmottant et al. [34] have reported a theoretical model that includes the contributions of shell viscosity and elasticity. Several studies have investigated the effects of a shell on microbubble ultrasound response by comparing experimental and theoretical results [31,35]. Although the acoustic characteristics of a cloud of microbubbles can be measured indirectly through classical pulse echo techniques, we used a dedicated optical observation system fitted with a high-speed microscopic camera that enables direct observation of a single microbubble and is capable of investigating the bubble shell motion, including nonspherical vibration mode [36], collapse [37], and bubble-bubble interactions [38]. However, the standard image resolution of these high-speed cameras is only around $0.5 \mu \mathrm{m}$, which is comparable to the bubble size, so large vibrational displacement amplitude $\Delta R$ of the bubble excited by large sound pressure is required for observation. Therefore, we previously developed a specific optical observational system that uses a laser Doppler vibrometer (LDV) [39], with which vibrations of small amplitudes $(<10 \mathrm{~nm})$ of a single microbubble can be measured through the Doppler effect of the reflected light. Because bubble vibration under ultrasound exposure is essentially a nonlinear phenomenon, the observation of the small-amplitude vibrations of a single microbubble in a linear region can increase our understanding of physical phenomena occurring in microbubbles.

The microscopic structure of the shell of a bubble and its rheology are the essential factors that determine bubble vibrational characteristics. A monolayer film of amphiphilic molecules is usually formed at the gas/liquid interface on the bubble surface [40-44]. Although the vibration amplitude of microbubbles coated with phospholipids or other surfactants under sonication is restrained by the 
viscoelasticity of the shell, the molecular film prevents the diffusion of the internal gas. Kabalnov et al. $[45,46]$ investigated the lifetime of fluorocarbon-stabilized phospholipid-coated microbubbles in the bloodstream theoretically and experimentally. Bubble lifetime was shown to depend on the gas pressure within the bubble, which is controlled by Laplace pressure, blood pressure, and oxygen metabolism, and the rate of the loss of the inner gas was determined from the bubble [47]. The discrepancy observed between theoretical and experimental data was subsequently determined to be due to a co-surfactant effect between fluorocarbon and phospholipids [48,49]. Considering the clinical use of microbubbles as drug carriers, the effect of ultrasound irradiation of a surfactant-coated bubble on its lifetime needed to be clarified.

Poloxamers are triblock copolymers consisting of a hydrophobic poly(propylene oxide) (PPO) segment flanked by two hydrophilic poly(oxyethylene oxide) (PEO) chains [40,41]. Poloxamers are candidates of choice for microbubble coating because some of them, including poloxamer 188 (Pluronic F-68), are routinely used in applications related to bioprocesses (e.g., to protect cell cultures against shear stress in reactors [50]) and pharmaceuticals (to sensitize cancers resistant to chemotherapy and in personal care products [51]). Pluronic F-68 is commonly used in microbubble preparation as a dispersant and foaming agent [47]

In our previous work, the vibration characteristics of air- and perfluorohexane (PFH)-saturated air microbubbles coated with Pluronic F-68 were evaluated and the relationship between the vibration characteristics of the microbubble and adsorption conditions of Pluronic F-68 molecules was investigated [44]. The variation of the surface pressure at the air/water or the PFH-saturated air/water interface (at $22 \pm 1{ }^{\circ} \mathrm{C}$ ) as a function of Pluronic F-68 concentration was obtained from dynamic adsorption curves measured by bubble profile analysis tensiometry (see the Supporting Information). The surface pressure increased (i.e., the surface tension diminished) as the Pluronic concentration increased. The relationship between surface pressure and Pluronic concentration indicated that the molecular film formed at the bubble surface underwent two successive phase transitions.

The present paper investigates microbubbles coated with the same linear (non-reticulated) polymeric surfactant, Pluronic F-68, when subjected to ultrasound waves, focusing on the relationships between Pluronic concentration and microbubble vibration characteristics and lifetime. We therefore used our specific single-bubble microbubble investigation technology to determine whether and to what extent the poloxamer interferes with the vibrational characteristics (amplitude and phase) and half-life of bubbles subjected to ultrasound irradiation. 


\section{Experimental Section}

Pluronic F-68 was purchased from Sigma-Aldrich $\left[(\mathrm{PEO})_{\mathrm{A}}(\mathrm{PPO})_{\mathrm{B}}(\mathrm{PEO})_{\mathrm{A}} ;\right.$ CAS Registry No. 9003-11-6; molecular weight $\left(M_{\mathrm{w}}\right)$ of $\sim 8400 \mathrm{~g} \mathrm{~mol}^{-1}$ according to the supplier and $\sim 9050 \mathrm{~g} \mathrm{~mol}^{-1}$ according to our light scattering experiments]. The degree of polymerization of each block $\left(N_{\mathrm{A}}=2 \times\right.$ 76 , and $\left.N_{\mathrm{B}}=29\right)$ was calculated from the nominal value of $M_{\mathrm{w}}$. The polydispersity index $\left(M_{\mathrm{w}} / M_{\mathrm{n}}=\right.$ 1.15 , where $M_{\mathrm{n}}$ is the number-average molecular weight) was obtained from gel permeation chromatography using THF as a solvent. The phospholipid, 1,2-dimyristoyl-sn-glycero-3-phosphocholine (DMPC), was purchased from NOF Corporation [CAS Registry No. 18194-24-6; Mw value of 677.9]. Pluronic F-68 and DMPC were used as the surfactants for microbubble coating. Ultrapure water was purchased from Fujifilm Wako Pure Chemical Corporation (CAS Registry No. 7732-18-5).

The vibration characteristics under ultrasound exposure of air- or PFH-saturated air-filled microbubbles coated with Pluronic F-68 or DMPC were measured optically. Figure 1 shows the system used for single-bubble vibration observation. A transparent cubic observation cell $(50 \times 50 \times 50$ $\mathrm{mm}$ ) was filled with an aqueous solution of Pluronic F-68 or DMPC with concentrations of 0 to $10^{-2}$ $\mathrm{mol} \mathrm{L}^{-1}$. Air or PFH microbubbles with a radius ranging from 20 to $150 \mu \mathrm{m}$ were generated in pure water by decompression in a syringe and then deposited gently on the surface of a glass plate fixed at the center of the cell using a micropipette. After the bubbles were attached to the glass plate, the Pluronic F-68 or DMPC molecules in the solution were progressively adsorbed on the bubble surface (gas/water interface). A previous paper by our group [44] reported that the adsorptions of Pluronic F-68 and PFH reaches a plateau after 10 to 60 min. Therefore, Pluronic F-68 or DMPC were allowed to adsorb on the microbubble surface for $60 \mathrm{~min}$ before they were exposed to the ultrasound irradiation. A bolt-clamped Langevin-type ultrasound piezoelectric transducer (Fuji Ceramics, Fujinomiya, Japan) was attached to the bottom of the observation cell. By exciting the transducer with a continuous sinusoidal electric signal at a resonance frequency of $38.8 \mathrm{kHz}$, a half-wavelength longitudinal resonance vibration mode was generated on the transducer and the sound wave was radiated toward the aqueous phase through the bottom of the cell. Multiple reflections of the incident sound wave between the surface of the aqueous solution and bottom of the cell produced an acoustic standing wave field in the vertical direction by controlling the solution level to $n \lambda / 2$, where $n$ is an integer and $\lambda$ is the wavelength of the sound wave in water. The resonance conditions and sound pressure distributions in the cell were maintained at constant values during all the measurements by monitoring the electric admittance of the transducer, which was maximized under the resonance conditions. Because the thickness of the glass plate was much smaller than the wavelength of the standing wave, the plate did not disturb the acoustic field. The microbubbles and glass plate were positioned in the antinodal plane of the standing wave to excite the bubble efficiently. An isolated single microbubble was selected to exclude bubble-bubble interaction effects. The sensor head of an 
LDV (NLV2500, PI Polytech, Waldbronn, Germany) with an objective lens (M Plan Apo 20× or $100 \times$, Mitutoyo, Kanagawa, Japan) was positioned above the observation cell to measure the radial vibration of the bubble in the standing wave. The laser beam of the LDV was focused perpendicularly to the top of the bubble's surface to measure the radial component of the vibration through the Doppler effect of the reflected light, and the initial bubble size was determined simultaneously using the CCD camera installed in the sensor head with an image resolution of 1.02 $\mu \mathrm{m}$ pixel $^{-1}$. The size of the focal spot of the LDV beam was $1.5 \mu \mathrm{m}$, which is relatively small when compared with the size of the bubble (tens of micrometers) used in this experiment. All the experiments were conducted at a temperature of $22{ }^{\circ} \mathrm{C}$. Altogether samples containing 1209 bubbles with different sizes were measured. Flexural vibration was also generated on the glass plate in the acoustic field and overlapped with the signal of the LDV. However, the vibration component of the glass plate was much smaller than that of the microbubble and can thus be considered negligible.

Because microbubble vibration under ultrasonic exposure is essentially a nonlinear phenomenon, the amplitude of the bubble vibration and vibration mode depend on the sound pressure amplitude; the vibrational amplitude increases nonlinearly and a nonspherical vibration mode involving the surface wave around the bubble surface is generated as the driving sound pressure increases. The sound pressure amplitude at the observational point was measured by a needle hydrophone (Type 8103, Brüel \& Kjær, Nærum, Denmark). In our experiments, the sound pressure amplitude was approximately $7.2 \mathrm{kPa}$, which is sufficiently small to allow observation of the linear spherical vibration of a microbubble [52]. The phase difference between the sinusoidal ultrasound wave to which the bubble was subjected and the bubble vibration driven by ultrasound was measured by monitoring the input current to the transducer to investigate the resonance characteristics of bubble vibrations.

\section{Results and Discussion}

The influence of the Pluronic F-68 and DMPC shells on micrometric bubble vibration under ultrasound exposure was investigated by measuring the vibrational amplitudes of a single bubble using an LDV under several different conditions. Figure 2 shows the relationship between the initial bubble radius $R_{0}$ and the vibrational displacement amplitude of the bubble $\Delta R$, which is called the resonance curve, for microbubbles coated with Pluronic F-68 and DMPC at concentrations ranging from 0 to $10^{-2} \mathrm{~mol} \mathrm{~L}^{-1}$. Around 60 samples were measured for each concentration. The vertical axis is $\Delta R$ normalized by $R_{0}$. An obvious peak of $\Delta R / R_{0}$ was observed for $R_{0}=40$ to $80 \mu \mathrm{m}$ under all the conditions investigated. Although the experimental results display large variations because the vibration of a microbubble under ultrasound irradiation is essentially a nonlinear phenomenon, the vibrational characteristics can be described by a Lorentzian fitting curve. This allows determination of the resonance bubble size and maximum $\Delta R$ when the sound pressure amplitude is relatively 
small ( $\sim 10 \mathrm{kPa})$ and the bubble vibration is assumed to be in a linear region [52].

In addition, the resonance bubble size can also be estimated from the phase difference between the driving sound pressure and bubble vibration because the phase difference inverts from $0^{\circ}$ to $180^{\circ}$ at the resonance size [52]; bubbles smaller (or larger) than the resonance size are contracted (or expanded) by the positive pressure from a continuous sinusoidal sound wave. Figure 3 shows the changes in phase difference with respect to $R_{0}$ for several Pluronic F-68 and DMPC concentrations. The phase difference shift depended on surfactant concentration. Compared with that of the data collected for the resonance curves (Fig. 2), the variation in the data is much smaller because the precision of the measurements of the phase difference is less affected by changes in the experimental conditions, such as the contact of the bubble with the plate or the temperature of the solution (the phase difference largely depends on bubble size and driving frequency). A sigmoid fit was used to determine the resonance bubble radius, which is defined as the radius obtained for a phase difference of $90^{\circ}$.

Figure 4 shows the relationship between Pluronic F-68 and DMPC concentrations and the resonance bubble radius estimated from the resonance curves (Fig. 2) and phase difference characteristics (Fig. 3). The plots and error bars in Fig. 4 express the resonance radius determined from each fitting curve and its standard deviation, respectively. These experimental results obtained by two distinct methods are in good agreement. The results concur on the same important points; that is, that the resonance bubble radius is always in the range of 60 to $70 \mu \mathrm{m}$ and essentially independent of Pluronic or DMPC concentration and inner gas (air or PFH). It should be noted that the resonance radius of a microbubble at $38.8 \mathrm{kHz}$ calculated using a theoretical model for the bubble vibration is $85 \mu \mathrm{m}$, and the resonance radius of a microbubble attached to a rigid body is slightly smaller than that of a free microbubble without contact [52].

Figure 5 depicts the relationship between Pluronic F-68 or DMPC concentration and maximum vibrational amplitude of a bubble with the resonance radius estimated from Fig. 4. The vertical axis shows the maximum $\Delta R$ normalized by the resonance bubble radius, and the plots and error bars respectively express the peak values of the optimized Lorenz curves and standard deviations calculated from the fitting curves and experimental results. The experimental results in Fig. 4 and 5 further confirm that the molecular films of Pluronic F-68 and DMPC have little influence on the vibration of the bubble in the standing-wave acoustic field under the measurement conditions. The radial vibration of a microbubble under low-amplitude ultrasound exposure can be approximated to a simple spring-mass-dashpot mechanical vibration model in the linear region. The numerical models based on Rayleigh-Plesset-like equation have been proposed to describe the dynamical response of an external ultrasound, with parameters for shell characteristics. The shell parameter composed of shell thickness, viscosity, stiffness, friction parameter and surface tension, shift the resonance radius derived from free bubble [31]. Although a higher Pluronic F-68 concentration results in lower 
surface tension at the air/water interface, as shown in the Supporting Information, and the elastic constant of the mechanical spring is decreased by the Pluronic F-68 molecules. These elastic constant and surface tension, which determine resonance radius, depend on the frequency of the ultrasound [31]. The frequency in this experiment, in comparison with ultrasound diagnostic equipment used in clinical practice, is remarkably low. Considering the vibrational characteristics simulated by Rooij et al. and Tu et al. [26-27,31], these parameters affect the resonance radius of a microbubble. In addition, the viscosity of the surrounding molecular film has a damping effect on bubble vibration that is proportional to the vibrational velocity [31]. These effects are enhanced on smaller bubbles driven with higher ultrasound frequency; the vibrational amplitude of micrometer-sized commercial ultrasound contrast agents is damped and the resonance radius increase in the megahertz range. However, our data for the resonance radius (Fig. 4) and the maximum $\Delta R$ (Fig. 5) show that the viscoelastic film did not change the resonance size and did not damp the bubble vibration significantly. This is because low ultrasound frequency $(38.8 \mathrm{kHz})$ and large microbubbles (tens of micrometers) were used in the experiments due to our observation system with low image resolution $\left(1.02 \mu \mathrm{m}\right.$ pixel $\left.^{-1}\right)$.

A surfactant film is known to hinder the diffusion of the internal gas of microbubbles into the surrounding media and increase the lifetime of the bubble. In addition, the solubility of inner gas also has great relevancy to the life time. According to the work by Kabalnov et al. $[45,46]$, the change in volume of a microbubble goes through three distinct stages. In the first stage, the microbubbles expand (and contract) rapidly until the interfacial tension and pressures in the internal gas and surrounding liquid are balanced. In the second stage, the bubbles contract slowly and the pressure inside the bubbles increases. In the final stage, the gas inside the bubble changes to a liquid and the bubble collapses rapidly; the change rate of a microbubble increases with decreasing bubble size. The life time was evaluated by measuring the temporal change in bubble radius under ultrasound exposure. Figure 6 displays the relationship between bubble radius and radius change rate in the acoustic standing wave. $\Delta R$ of the bubbles was almost independent of Pluronic or DMPC concentration and inner gases (see Fig. 2 and 5). The radius change rate was calculated from the change in the average bubble radius between $10 \mathrm{~s}$ and 1 hour in the continuous acoustic standing-wave field, and the average values for $2.5-\mu \mathrm{m}$ radius intervals were plotted. In the experimental results shown in Fig. 6, the change rates were separated clearly between air-filled and PFH-filled bubbles; the change rates of the PFH-filled bubble were almost constant in all the initial bubble radius since PFH has low solubility. On the other hand, the radius change rate of air-filled bubble decreased as the initial radius decreases in all cases because the Laplace pressure $\Delta P=2 \sigma / R$ ( $\sigma$. surface tension; $R$ : bubble radius) increases with decreasing bubble size. In addition, in case of air-filled bubble, higher Pluronic concentrations result in smaller radius changes and smaller error bars because the surfactant film hinders the diffusion of the internal gas. 
Figure 7 depicts the relationship between initial radius and volume change rate of the microbubbles in the acoustic standing wave. The volume change was calculated from the experimental results in Fig. 6. Although the variation of the radius was smaller for larger bubbles at air bubble, as shown in Fig. 6 , the variation of the volume increased with bubble size. It should be noted that the maximum volume change was observed for a bubble radius of around $60 \mu \mathrm{m}$ at air-filled bubble, which corresponds to the resonance radius of the microbubbles (see Fig. 4). Therefore, these results mean that the lifetime of the microbubbles depends on their vibrational amplitude under ultrasound exposure, and that a larger vibration amplitude accelerates the diffusion of the internal gas into the surrounding media through the molecular film. The half-life of a microbubble was defined as the time during which the volume of bubbles halved and was calculated from the results in Fig. 7. Figure 8 presents the relationship between Pluronic F-68 concentration and half-life of the microbubbles close to the resonance size under ultrasound exposure. The results clearly demonstrate that a higher concentration of Pluronic F-68 prolongs the lifetime of the air-filled microbubbles.

\section{Conclusions and Perspectives}

The vibrational characteristics and lifetime of individual air- and PFH-filled microbubbles coated with a film of the block copolymer Pluronic F-68 and phospholipid DMPC exposed to ultrasound were investigated. The vibration of single bubbles in an acoustic standing wave was measured by laser Doppler vibrometry as a function of bubble radius. The maximum vibrational amplitude and resonance size of the bubbles showed little dependence on the presence and concentration of Pluronic. In other words, the polymeric surfactant was found to interfere only minimally with the vibrational qualities and resonance of the microbubbles, which remained similar to those of naked bubbles. On the other hand, the lifetime of the bubbles with coated Pluronic F-68 and DMPC under ultrasound exposure depended on inner gas, bubble size, vibrational amplitude, and concentration of shell material. Remarkably, higher Pluronic concentrations led to longer lifetime.

\section{Acknowledgment}

This work was partially supported by the Heiwa Nakajima Foundation. We thank Natasha Lundin, $\mathrm{PhD}$, from Edanz Group (www.edanzediting.com/ac) for editing a draft of this manuscript.

\section{References.}

[1] Zhou, T.; Gai, W.; Yang, H.; Zhang, H.; Hao, M., Yuan, L.; Liu, J.; Zhang, L. Yang, Y.; Liu, X.; Deng, J.; Zhao, P.; Yang, G.; Duan, Y.; Annexin V conjugated nanobubbles: A novel ultrasound contrast agent for in vivo assessment of the apoptotic response in cancer therapy. $J$. Control. Release 2018, 276, 113-124.

[2] Wallace, N.; Wrenn, S. P. Ultrasound triggered drug delivery with liposomal nested 
microbubbles. Ultrasonics 2015, 63, 31-38.

[3] Wilson, K. E.; Wang, T. Y.; Willmann, J. K. Acoustic and photoacoustic molecular imaging of cancer. J. Nucl. Med. 2013, 54, 1851-1854.

[4] Chong, W. K.; Papadopoulou, V.; Dayton, P. A. Imaging with ultrasound contrast agents: current status and future. Abdom. Radiol. 2018, 43, 762-772.

[5] van Rooij, T.; Skachkov, I.; Beekers, I.; Lattwein, K. R.; Voorneveld, J. D.; Kokhuis, T. J. A.; Bera, Deep.; Luan, Y.; van der Steen, A. F. W.; de Jong, N.; Kooiman, K. Viability of endothelial cells after ultrasound-mediated sonoporation: Influence of targeting, oscillation, and displacement of microbubbles. J. Control. Release 2016, 238, 197-211.

[6] Lee, M.; Lee, E. Y.; Lee, D.; Park, B. J. Stabilization and fabrication of microbubbles: Applications for medical purposes and functional materials. Soft Matter 2015, 11, 2067-2079.

[7] Paefgen,V.; Doleschel, D.; Kiesling, F. Evolution of contrast agents for ultrasound imaging and ultrasound-mediated drug delivery. Front. Pharmacol. 2015, 6, 197.

[8] Wang, J.; Barback, C. V.; Ta, C. N.; Weeks, J.; Gude, N.; Mattrey, R. F.; Blair, S. L.; Trogler, W. C.; Lee, H.; Kummel, A. C. Extended lifetime in vivo pulse stimulated ultrasound imaging. IEEE Trans. Med. Imaging 2018, 37, 222-229.

[9] Jin, Q.; Lin, C. Y.; Kang, S. T.; Chang Y. C.; Zheng, H.; Yang, C. M.; Yeh, C. K. Superhydrophobic silica nanoparticles as ultrasound contrast agents. Ultrason. Sonochem. 2017, 36, 262-269.

[10] Suzuki, R.; Takizawa, T.; Negishi, Y.; Utoguchi, N.; Maruyama, K. Effective gene delivery with novel liposomal bubbles and ultrasonic destruction technology. Int. J. Pharm. 2008, 354, $49-55$.

[11] Suzuki, R.; Oda, Y.; Utoguchi, N.; Namai, E.; Taira, Y.; Okada, N.; Kadowaki, N.; Kodama, T.; Tachibana, K.; Maruyama, K. A novel strategy utilizing ultrasound for antigen delivery in dendritic cell-based cancer immunotherapy. J. Control. Release 2009, 133, 198-205.

[12] Suzuki, R.; Namai, E.; Oda, Y.; Nishiie, N.; Otake, S.; Koshima, R.; Hirata, K.; Taira, Y.; Utoguchi, N.; Negishi, Y.; Nakagawa, S.; Maruyama, K. Cancer gene therapy by IL-12 gene delivery using liposomal bubbles and tumoral ultrasound exposure. J. Control. Release 2010, $142,245-250$.

[13] Negishi, Y.; Endo, Y.; Fukuyama, T.; Suzuki, R.; Takizawa, T.; Omata, D.; Maruyama, K.; Aramaki, Y. Delivery of siRNA into the cytoplasm by liposomal bubbles and ultrasound. $J$. Control. Release 2008, 132, 124-130.

[14] Suzuki, R.; Takizawa, T.; Kuwata, Y.; Mutoha, M.; Ishiguro, N.; Utoguchi, N.; Shinohara, A.; Eriguchi, M. Effective anti-tumor activity of oxaliplatin encapsulated in transferrinPEG-liposome. Int. J. Pharm. 2008, 346, 143-150.

[15] Suzuki, R.; Takizawa, T.; Negishi, Y.; Hagisawa, K.; Tanaka, K.; Sawamura, K.; Utoguchi, N.; 
Nishioka, T.; Maruyama, K. Gene delivery by combination of novel liposomal bubbles with perfluoropropane and ultrasound. J. Control. Release 2007, 117, 130-136.

[16] Lalzad, A.; Wong, F.; Singh, N.; Coombs, P.; Brockley, C.; Brennan, S.; Ditchfield, M.; Rao, P.; Watloms, A.; Watkins, A.; Saxton, V.; Schneider, M. Knowledge of safety, training, and practice of neonatal cranial ultrasound: A survey of operator. J. Ultrasound Med. 2018, 37, $1411-1421$.

[17] McDannold, N.; Vykhodtseva, N.; Hynynen, K. Blood-Brain Barrier disruption induced by focused ultrasound and circulating preformed microbubbles appears to be characterized by the mechanical index. Ultrasound Med. Biol. 2008, 34, 834-840.

[18] Barnett, S. B.; Maulik, D. Guidelines and recommendations for safe use of doppler ultrasound in perinatal applications. J. Matern. Fetal Med. 2001, 10, 75-84.

[19] Haar, G. T. Ultrasound bioeffect and safety. Proc. Inst. Mech. Eng. Part H 2010, 224, 363373.

[20] Kubota, R.; Yamashita, Y.; Kenmotsu, T.; Yoshikawa, Y.; Yoshida, K.; Watanabe, Y.; Imanaka, T.; Yoshikawa, K. Double-strand breaks in genome-sized DNA caused by ultrasound. ChemPhysChem 2017, 18, 959-964.

[21] Yoshida, K.; Ogawa, N.; Kagawa, Y.; Tabata, H.; Watanabe, Y.; Kenmotsu, T.; Yoshikawa, Y.; Yoshikawa, K. Effect of low-frequency ultrasound on double-strand breaks in giant DNA molecles. Appl. Phys. Lett. 2013, 103, 063705.

[22] van Wamel, A.; Kooiman, K.; Harteveld, M.; Emmer, M.; ten Cate, F. J.; Versluis, M.; de Jong, N. Vibrating microbubbles poking individual cells: Drug transfer into cells via sonoporation. $J$. Control. Release 2006, 112, 149-155.

[23] Bekeredjian, R.; Grayburn, P. A.; Shohet, R. V. Use of ultrasound contrast agents for gene or drug delivery in cardiovascular medicine. J. Am. Coll. Cardiol. 2005, 45, 329-335.

[24] Ward, M.; Wu, J.; Chiu, J. F. Ultrasound-induced cell lysis and sonoporation enhanced by contrast agents. J. Acoust. Soc. Am. 1999, 105, 2951-2957.

[25] Karshafian, R.; Bevan, P. D.; Williams, R.; Samac, S.; Burns, P. N. Sonoporation by ultrasound-activated microbubble contrast agent: Effect of acoustic exposure parameters on cell membrane permeability and cell viability. Ultrasound Med. Biol. 2009, 35, 847-860.

[26] van Rooij, T.; Luan, Y.; Renaud, G.; van der Steen, A. F. W.; de Jong, N.; Kooiman, K. Acoustical response of DSPC versus DPPC lipid-coated microbubbles. Proc. 2013 IEEE Int. Ultrason. Symp. 2013, 310-313.

[27] van Rooij, T.; Luan, Y.; Renaud, G.; van der Steen, A. F. W.; de Jong, N.; Kooiman, K. Non-linear response and viscoelastic properties of lipid-coated microbubbles: DSPC versus DPPC. Ultrasound Med. Biol. 2015, 41, 1432-1445.

[28] Chatterjee, D.; Sarkar, K. A Newtonian rheological model for the interface of microbubble 
contrast agents. Ultrasound Med. Biol. 2003, 29, 1749-1757.

[29] Sijl, J.; Gaud, E.; Frinking, P. J. A.; Arditi, M.; de Jong, N.; Lohse, D.; Versluis, M. Acoustic characterization of single ultrasound contrast agent microbubbles. J. Acoust. Soc. Am. 2008, $124,4091-4097$.

[30] van der Meer, S. M.; Dollet, B.; Voormolen, M. M.; Chin, C. T.; Bouakaz, A.; de Jong, N.; Versluis, M.; Lohse, D. Microbubble spectroscopy of ultrasound contrast agents. J. Acoust. Soc. Am. 2007, 121, 648-656.

[31] Tu, J.; Guan, J.; Qiu, Y.; Matula, T. J. Estimating the shell parameters of SonoVue ${ }^{\circledR}$ microbubbles using light scattering, J. Acoust. Soc. Am. 2009, 126, 2954-2962.

[32] Church, C. C. The effects of an elastic solid surface layer on the radial pulsations of gas bubbles. J. Acoust. Soc. Am. 1995, 97, 1510-1521.

[33] Chatterjee, D.; Sarkar, K. A Newtonian rheological model for the interface of microbubble contrast agents. Ultrasound Med. Biol. 2003, 29, 1749-1757.

[34] Marmottant, P.; van der Meer, S.; Emmer, M.; Versluis, M.; de Jong, N.; Hilgenfeldt, S.; Lohse, D. A model for large amplitude oscillations of coated bubbles accounting for buckling and rupture. J. Acoust. Soc. Am. 2005, 118, 3499-3505.

[35] Yoshida, K.; Morioka, S.; Kagawa, Y.; Koyama, D.; Watanabe, Y. Power-law dependence describing subharmonic generation from a non-spherically oscillating bubble. Acoust. Sci. \& Tech. 2015, 36, 191-200.

[36] Yoshida, K.; Nakatani, S.; Tsukamoto, A.; Ushida, T.; Watanabe, Y. Effect of collapsing bubble in ultrasonic field on soft material. Jpn. J. Appl. Phys. 2008, 47, 4200-4204.

[37] Koyama, D.; Osaki, A.; Kiyan, W.; Watanabe, Y. Acoustic destruction of a micro-capsule having a hard plastic shell. IEEE Trans. Ultrason., Ferroelect., Freq. Contr. 2006, 53, 1314 1321.

[38] Yoshida, K.; Fujikawa, T.; Watanabe, Y. Experimental investigation on reversal of secondary Bjerknes force between two bubbles in ultrasonic standing wave. J. Acoust. Soc. Am. 2011, 130, 135-144.

[39] Koyama, D.; Kotera, H.; Kitazawa, N.; Yoshida, K.; Nakamura, K.; Watanabe, Y.; Vibration of a single microcapsule with a hard plastic shell in an acoustic standing wave field. IEEE Trans. Ultrason., Ferroelect., Freq. Contr. 2011, 58, 737-743.

[40] Muñoz, M. G.; Monroy, F.; Ortega, F.; Rubio, R. G.; Langevin, D. Monolayer of symmetric triblock copolymer at the air-water interface. 1. Equilibrium properties. Langmuir 2000, 16, 1083-1093.

[41] Muñoz, M. G.; Monroy, F.; Ortega, F.; Rubio, R. G.; Langevin, D.; Dominique, L. Monolayer of symmetric triblock copolymer at the air-water interface. 2. Adsorption kinetics. Langmuir 2000, 16, 1094-1101. 
[42] Svitova, T. F.; Radke, C. J. AOT and Pluronic F68 coadsorption at fluid/fluid interfaces: A continuous-flow tensiometry study. Ind. Eng. Chem. Res. 2005, 44, 1129-1138.

[43] Nguyen, P. N.; Waton, G.; Vandamme, T.; Krafft, M. P. Behavior of an adsorbed phospholipid monolayer submitted to prolonged periodical surface density variations. Angew. Chem., Int. Ed. 2013, 125, 6532-6536.

[44] Ando, Y.; Tabata, H.; Sanchez, M.; Cagna, A.; Koyama, D.; Krafft, M. P. Microbubbles with a self-assembled poloxamer shell and a fluorocarbon inner gas. Langmuir 2016, 32, 12461 12467.

[45] Kabalnov, A.; Klein, D.; Pelura, T.; Schutt, E.; Weers, J. Dissolution of multicomponemt microbubbles in the blood stream 1. Theory. Ultrasound Med. Biol. 1998, 24, 739-749.

[46] Kabalnov, A.; Bradley, J.; Flaim, S.; Klein, D.; Pelura, T.; Peters, B.; Otto, S.; Reynolds, J.; Schutt, E.; Weers, J. Dissolution of multicomponent microbubbles in the blood stream 2. Experiment. Ultrasound Med. Biol., 1998, 24, 751-760.

[47] Schutt, E. S.; Klein, D. H.; Mattrey, R. M.; Riess, J. G. Injectable microbubbles as contrast agents for diagnostic ultrasound imaging: The key role of perfluorochemicals. Angew. Chem., Int. Ed. 2003, 42, 3218-3235.

[48] Nguyen, P. N.; Trinh Dang, T. T.; Waton, G.; Vandamme, T.; Krafft, M. P. A nonpolar, nonamphiphilic molecule can accelerate adsorption of phospholipids and lower their surface tension at the air/water interface. ChemPhysChem 2011, 12, 2646-2652.

[49] Szijjarto, C.; Rossi, S.; Waton, G.; Krafft, M. P. Effects of perfluorocarbon gases on the size and stability characteristics of phospholipid-coated microbubbles - Osmotic effect versus interfacial film stabilization. Langmuir 2012, 28: 1182-1189.

[50] Tharmalingam, T.; Ghebeh, H.; Wuerz, T.; Butler, M. Pluronic enhances the robustness and reduces the cell attachement of mammalian cells. Mol. Biotechnol. 2008, 39, 167-177.

[51] Alakhova, D. Y.; Kabanov, A. V. Pluronic and MDR reversal: An update. Mol. Pharmaceutics 2014, 11, 2566-2578.

[52] Yoshikawa, T.; Kotera, H.; Yoshida, K.; Koyama, D.; Nakamura, K.; Watanabe, Y. Measurement of the resonant characteristics of a single bubble vibration by using a laser Doppler vibrometer. Jpn. J. Appl. Phys. 2011, 50, 07 HE04.

[53] Hoff, L. Acoustic Characterization of Contrast Agents for Medical Ultrasound Imaging; Kluwer: Dordrecht, The Netherlands, 2001. 


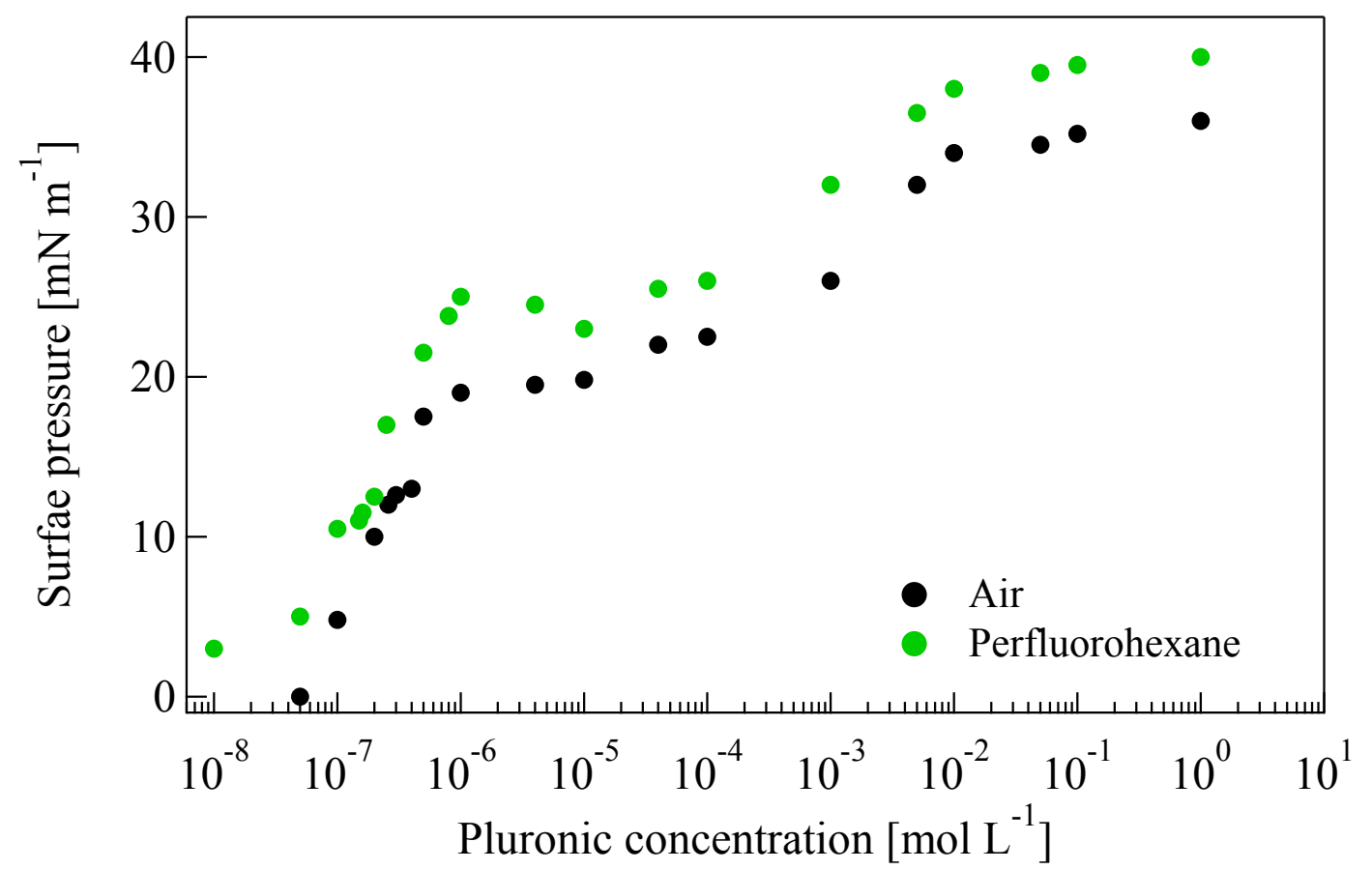

Supporting Information: Variation of the surface pressure at an air/water and PFH/water interface as a function of Pluronic F-68 concentration at $22 \pm 1{ }^{\circ} \mathrm{C}$. 


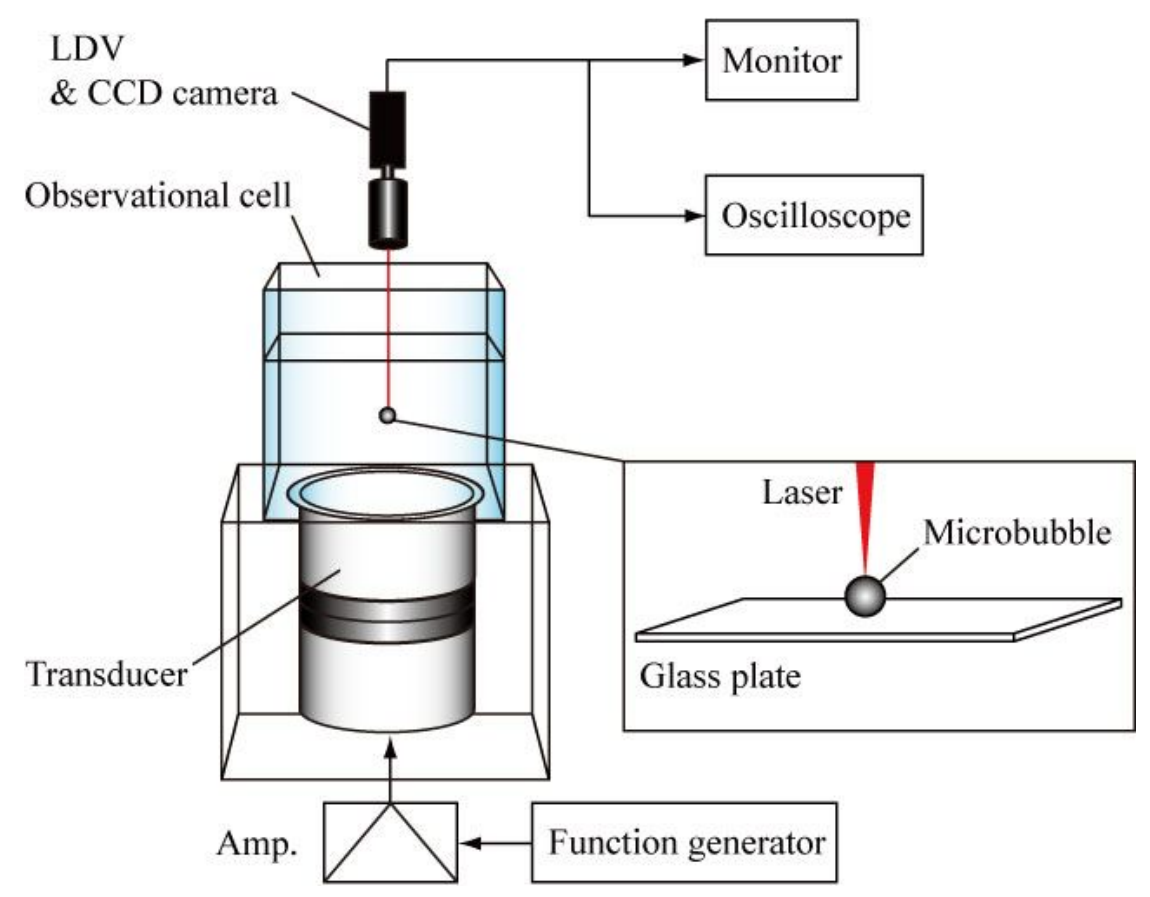

Figure 1. System for single-bubble vibration observation using an ultrasound transducer and laser Doppler vibrometer (LDV). 

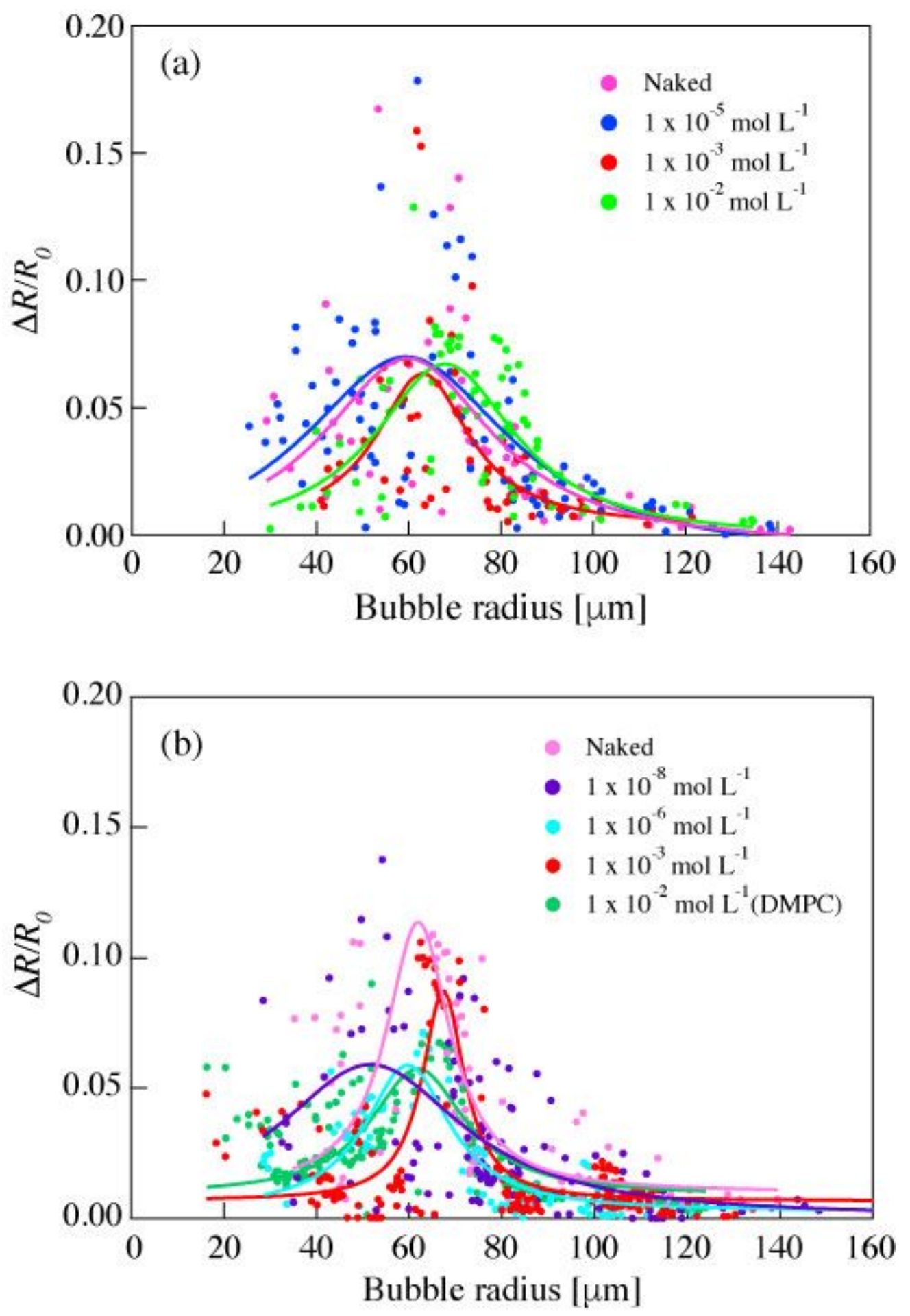

Figure 2. Relationships between the initial bubble radius and normalized displacement amplitude for (a) air-filled microbubbles $\left(\Delta R / R_{0}\right)$ coated with Pluronic F-68 at concentrations of 0 (naked), $1 \times$ $10^{-5}, 1 \times 10^{-3}$, and $1 \times 10^{-2} \mathrm{~mol} \mathrm{~L}^{-1}$ and (b) PFH-filled microbubbles $\left(\Delta R / R_{0}\right)$ coated with Pluronic F-68 and DMPC at concentrations of 0 (naked), $1 \times 10^{-8}, 1 \times 10^{-6}, 1 \times 10^{-3} \mathrm{~mol} \mathrm{~L}^{-1}$ and $1 \times 10^{-3}$ mol L ${ }^{-1}$ (DMPC). Fitting curves were obtained using the Lorentz distribution. 

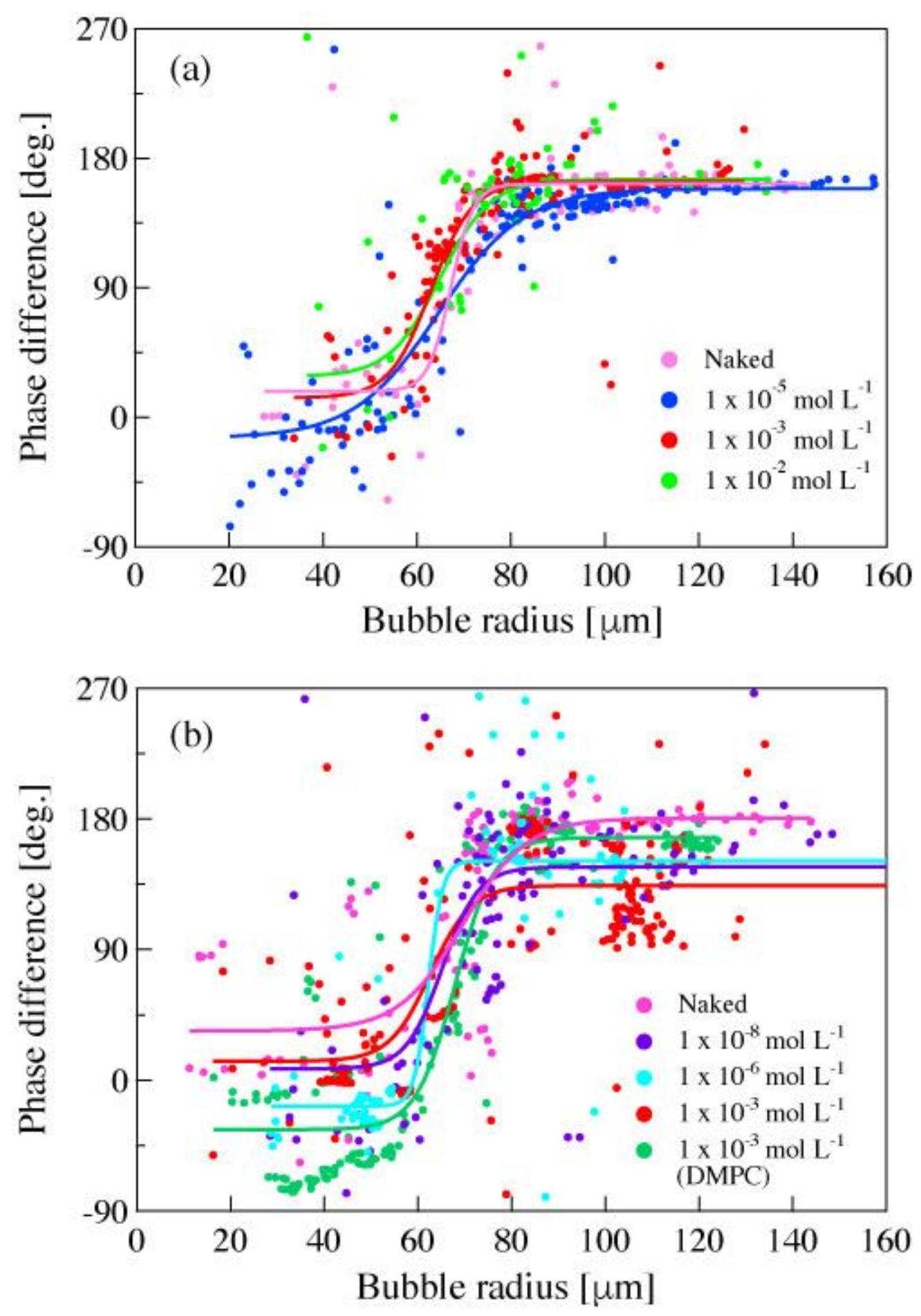

Figure 3. Relationships between bubble radius and phase difference between the sound pressure amplitude and vibration of (a) air-filled microbubbles coated with Pluronic F-68 with concentrations of 0 (naked), $1 \times 10^{-5}, 1 \times 10^{-3}$, and $1 \times 10^{-2} \mathrm{~mol} \mathrm{~L}^{-1}$ and (b) PFH-filled microbubbles $\left(\Delta R / R_{0}\right)$ coated with Pluronic F-68 and DMPC at concentrations of 0 (naked), $1 \times 10^{-8}, 1 \times 10^{-6}, 1 \times 10^{-3}$ mol L ${ }^{-1}$ and $1 \times 10^{-3} \mathrm{~mol} \mathrm{~L}^{-1}$ (DMPC). Fitting curves were obtained using the sigmoid distribution. 


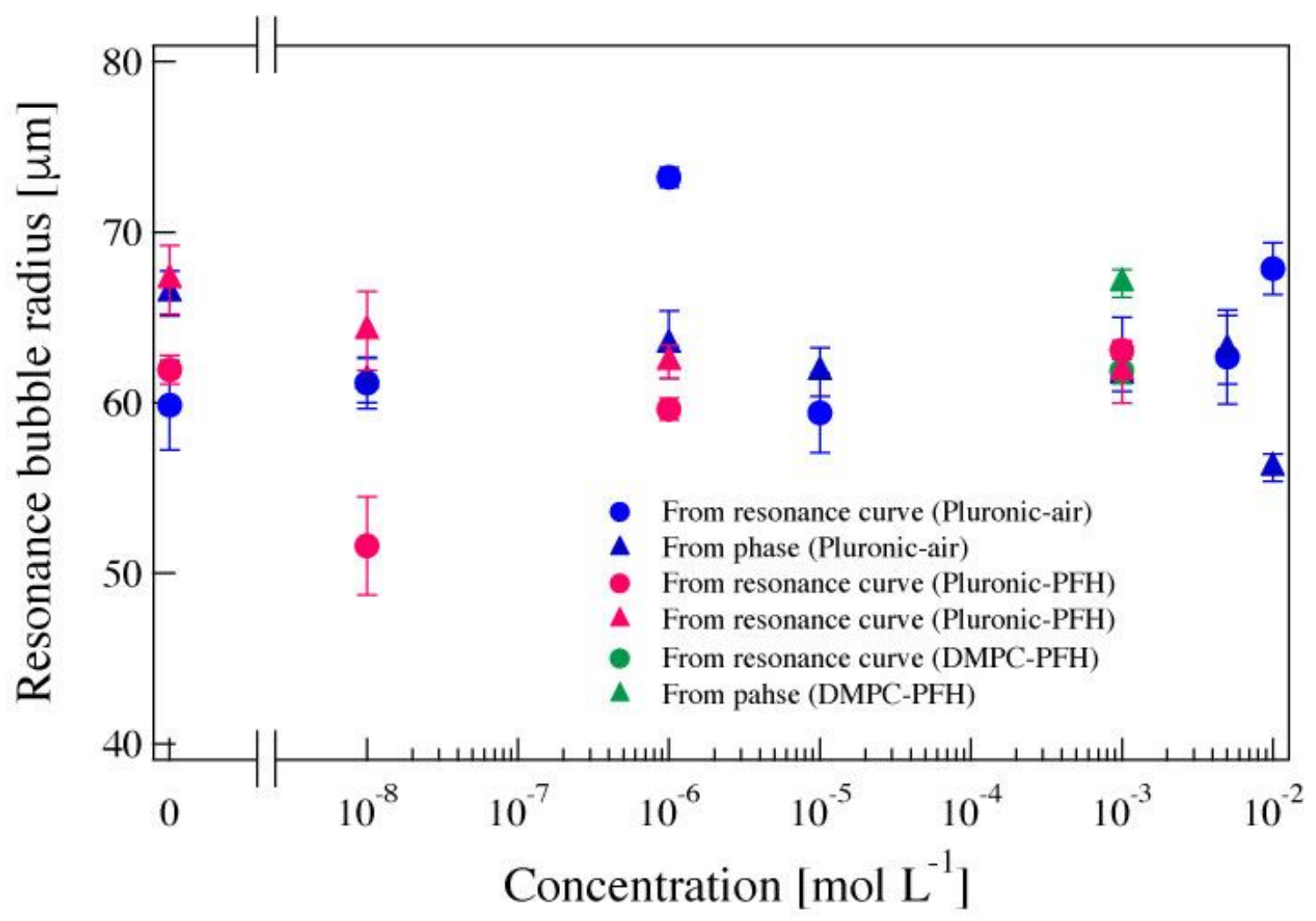

Figure 4. Relationship between Pluronic F-68 concentration and the resonance bubble radius estimated from the resonance curves (Fig. 2) and phase characteristics (Fig. 3). The blue circle and triangle describe air-bubble coated with Pluronic-F68. The pink circle and triangle describe PFH-bubble coated with Pluronic-F68. The green circle and triangle describe PFH-bubble coated with DMPC. 


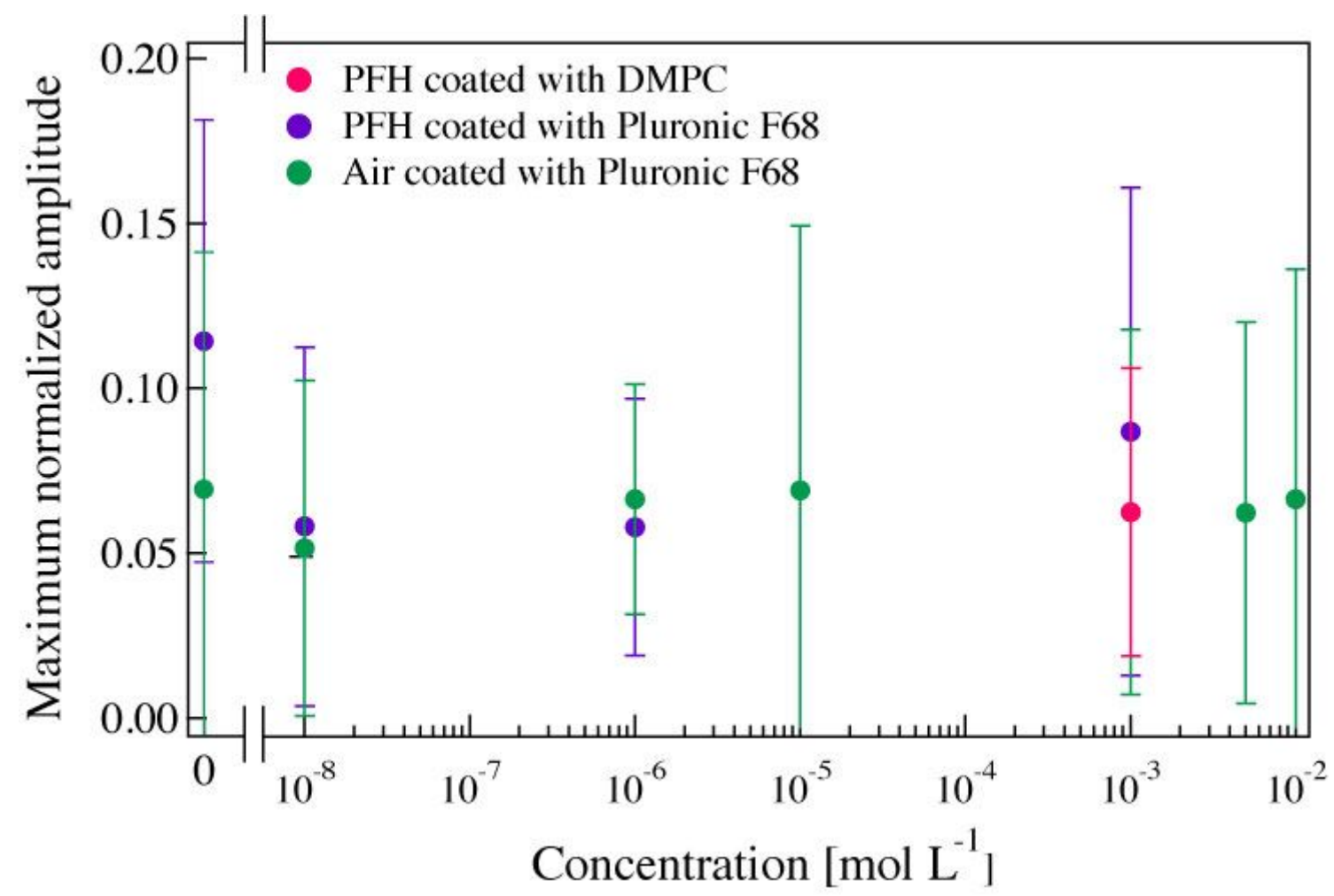

Figure 5. Relationship between Pluronic F-68 concentration and the maximum vibration amplitude of the microbubbles. The green circle describes air-bubble coated with Pluronic-F68. The purple one describes PFH-bubble coated with Pluronic-F68. The pink one describes PFH-bubble coated with DMPC. 


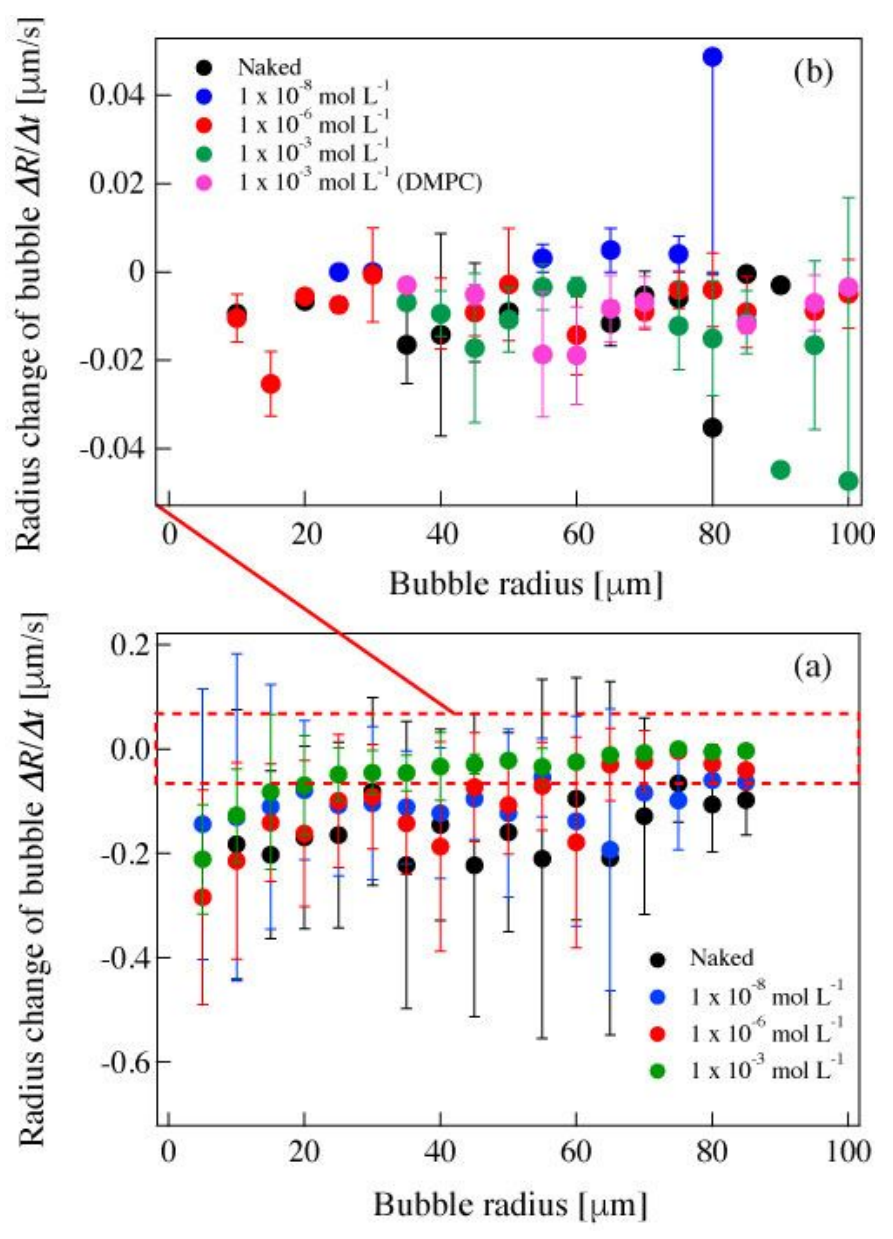

Figure 6. Temporal changes in the radius of (a) air-bubble coated with Pluronic-F68 and (b) PFH-bubble coated with Pluronic-F68 and DMPC. 


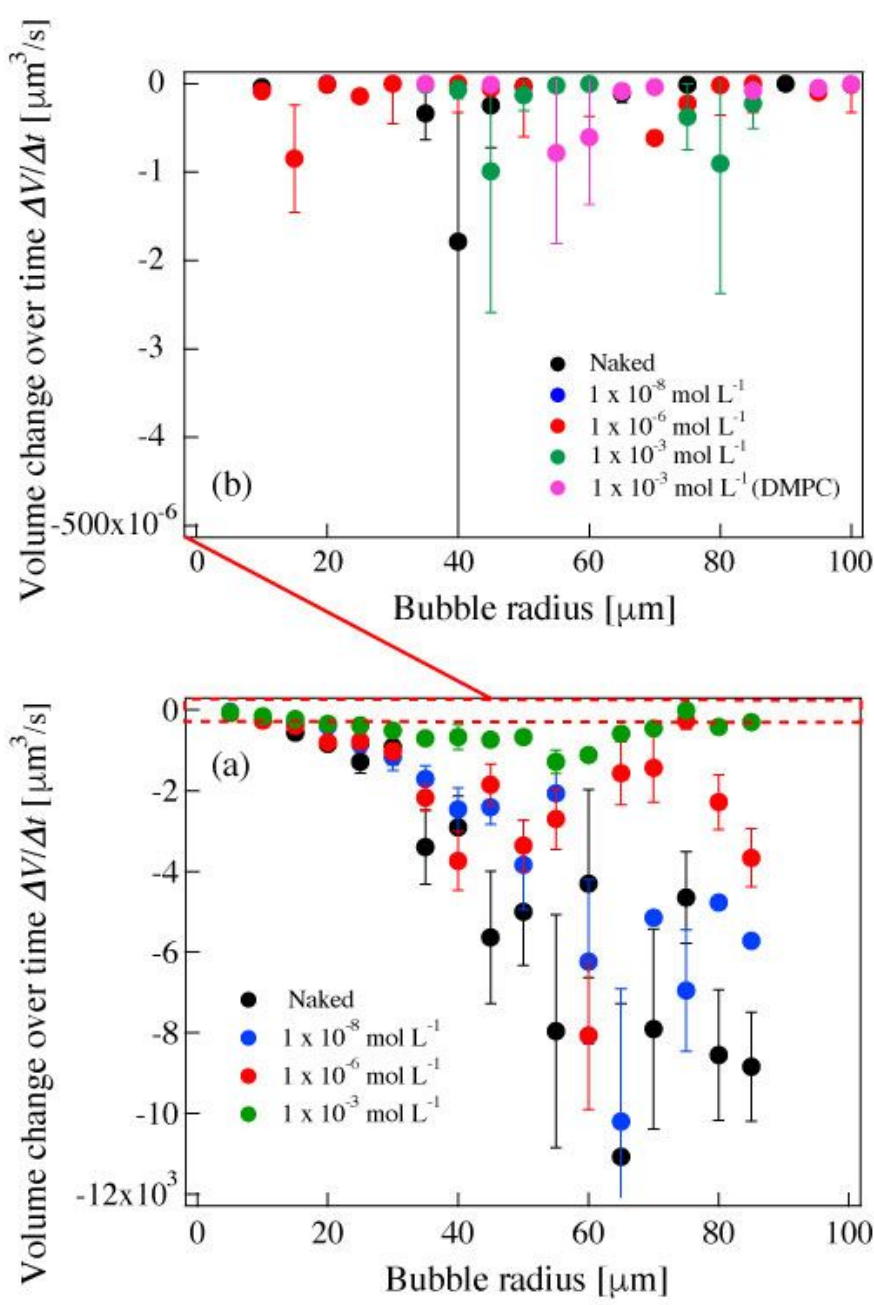

Figure 7. Temporal changes in the volume of (a) air-bubble coated with Pluronic-F68 and (b) PFH-bubble coated with Pluronic-F68 and DMPC. 


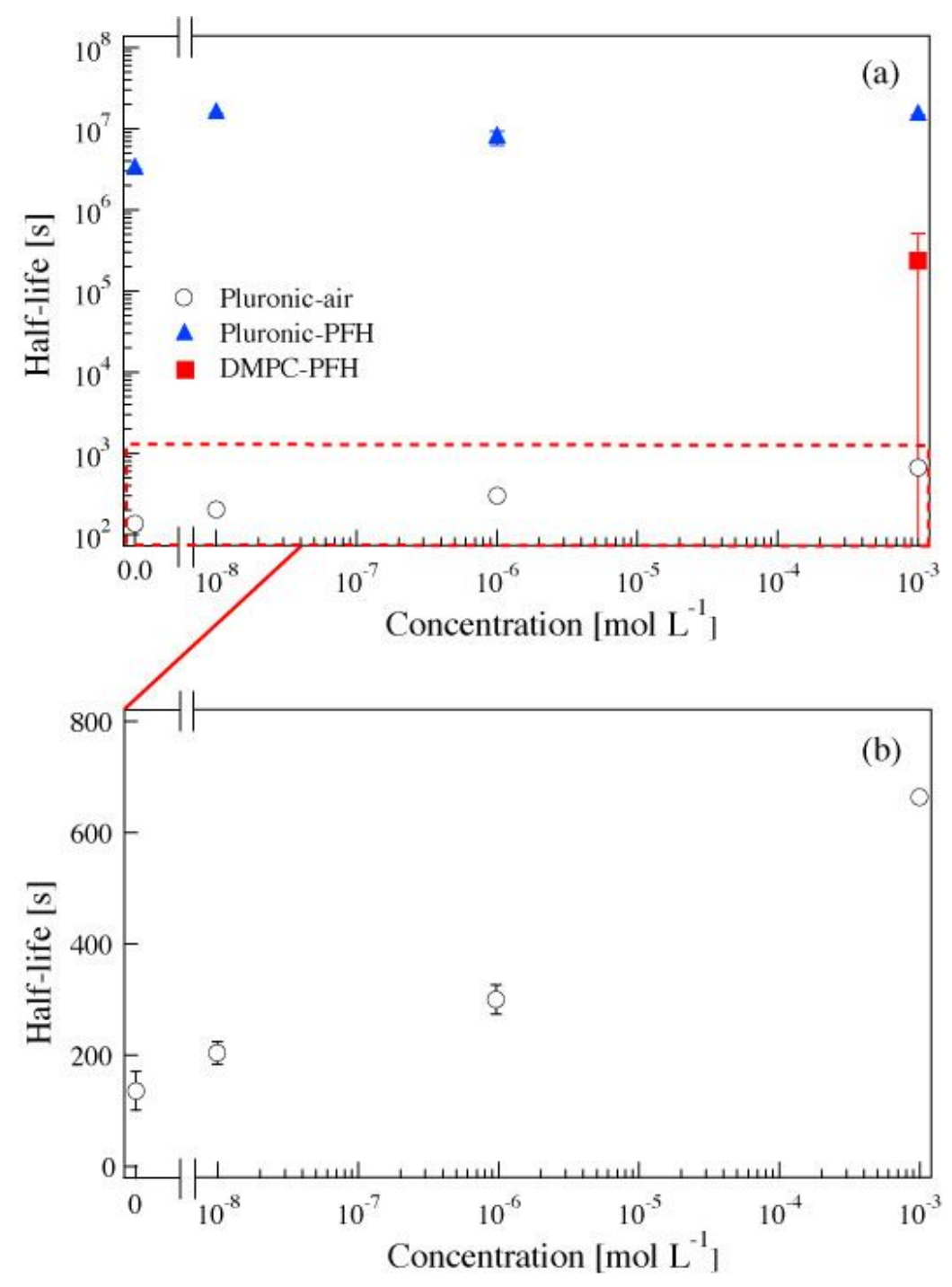

Figure 8. Relationship between concentration of Pluronic F-68 and DMPC and the half-life of microbubbles resonating under ultrasound exposure at $38.8 \mathrm{kHz}$. The hollow circle shows air-bubble coated with Pluronic-F68 and the triangle shows PFH-bubble coated with Pluronic-F68. The square shows PFH-bubble coated with DMPC. 